
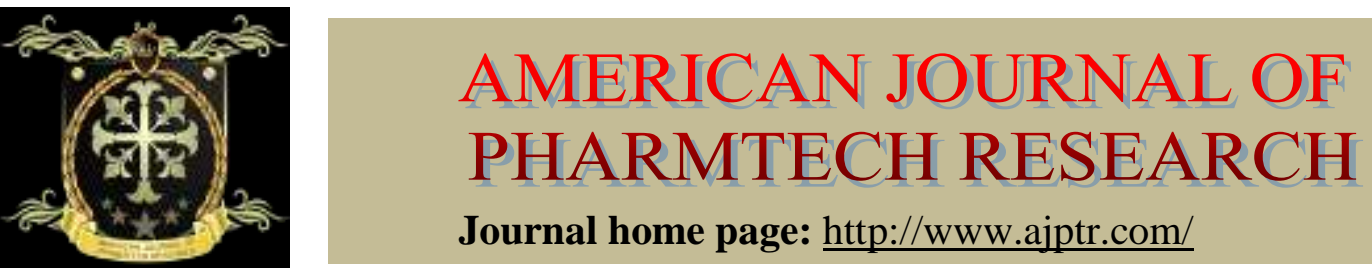

Journal home page: http://www.ajptr.com/

\title{
Evaluation of Powder Drug Layering Technique as Possible means of Abuse Deterrent Formulation
}

\author{
Saripadiya Nimesh $D^{1 *}$, Bhatt Varun ${ }^{2}$, Parsa Kartik ${ }^{2}$, Fanda Anuj K ${ }^{2}$ \\ 1.Department of Pharmaceutics, Institute of Pharmacy, Nirma University, Ahmedabad-382481. \\ 2.Sun Pharmaceutical industries Ltd., Gurgaon, Haryana-122001.
}

\section{ABSTRACT}

Abuse and misuse of prescription opioids is a significant public health concern. The strategies used to confer abuse-deterrent properties on opioid abuse deterrent formulations (ADFs). The objective of this study was to develop techniques for an abuse deterrent (AD) platform utilizing the Granurex process. For the preparation of abuse deterrent extended release formulation core material was layered with dry active pharmaceutical ingredient with the help of Granurex technology and after the drug layering suitable polymeric coat was applied to make formulation crushed resistance and resistance to dose dumping. Formulation optimization was accomplished by utilizing full factorial design of experiments to determine the effect of the three formulation factors: Ethyl cellulose 45 cps, white wax and carbopol 974P NF; each of which was studied at three levels on crushed resistance (CR) attributes of the produced extended release pellets. Suitable formulation ingredients were employed as carrier matrices and processing aids. All of the formulations were evaluated for the crushed resistance and dose dumping attributes, such as crushing strength, extraction studies of drug in different levels of solvents and particle size . All of the design of experiments formulations demonstrated sufficient hardness and elasticity, and could not be reduced into fine particles, which is a desirable feature to prevent snorting. In addition, all of the formulations exhibited good gelling tendency in water with minimal extraction of drug in the aqueous medium. Moreover, Carbopol 974P NF, in combination with white wax, could be utilized to produce pellets with crushed resistance potential. Granurex has been demonstrated to be a viable technique with a potential of develop novel $\mathrm{AD}$ formulations.

Keywords: Abuse deterrent formulations, Crushed resistance 


\section{INTRODUCTION}

The Aim and Objective of these work is to identify abuse deterrent properties of extended release pellets and differentiate of this properties of extended release pellets with reference products by several tests. To describes various type of studies like dose dumping studies with $40 \%$ alcohol, drug release studies in different media, hardness, Crushability of the pellets.

\section{MATERIALS AND METHOD}

\section{Materials}

Oxycodone hydrochloride was obtained as a gift sample from Sun Pharmaceutical Laboratories Limited, Gurgaon. Microcrystalline sphere was obtained from cellets, Aerosil and talc Powder obtained from Evonik and Brenntag specialties, White wax was Purchased from Bramble berry. Other excipients used were of standard pharmaceutical grade. Isopropyl alcohol was used throughout the experiment. Ethyl cellulose 45 cps was obtained from colorcon. Cellulose acetate CA-398-10NF/EP was obtained from EASTMAN. Name of equipment used for these are Granurex, Glatt(Bottom spray).

\section{Identification of API}

Oxycodone hydrochloride, is medicine mostly use in the treatment of pain management and for the persons who are in the stress. This drug was typically administered by the oral route(mouth). It is sometimes used to treat or reduce the pain after the big surgery or the surgery like cancer. Oxycodone hydrochloride is classified as a mu-receptor agonist or sometime mild analgesics. Mode of action of Oxycodone hydrochloride It is weak inhibitor of prostaglandins receptors. Sometime it act as an inhibit COX receptor in the brain. Sometimes it acts as an COX-2 inhibitor. Oxycodone hydrochloride solubility. Water Solubility=14000 mg/L (at $25^{\circ} \mathrm{C}$ ), $14 \mathrm{mg} / \mathrm{mL}$ at 25 ${ }^{\circ} \mathrm{C}$. Very slightly soluble in cold water, soluble in boiling water. Freely soluble in alcohol. Soluble in methanol, ethanol, dimethyl formamide, ethylene dichloride, acetone, ethyl acetate; slightly soluble in ether. Practically insoluble in petroleum ether, pentane, benzene.

Table 1 Solubility values of drug in different media

\begin{tabular}{llllll}
\hline $\begin{array}{l}\text { Sr } \\
\text { no }\end{array}$ & Drug & 0.1N HCl & $\begin{array}{l}\text { Phthalate } \\
\text { buffer } \mathbf{~ p H ~ 4 . 5 ~}\end{array}$ & $\begin{array}{l}\text { Phosphate } \\
\text { buffer pH 6.8 }\end{array}$ & $\begin{array}{l}\text { Phosphate } \\
\text { buffer pH 7.4 }\end{array}$ \\
\hline 1 & $\begin{array}{l}\text { Oxycodone } \\
\text { hydrochloride }\end{array}$ & $0.0894 \mathrm{gm} / \mathrm{ml}$ & $0.0061 \mathrm{gm} / \mathrm{ml}$ & $0.0056 \mathrm{gm} / \mathrm{ml}$ & $0.0049 \mathrm{gm} / \mathrm{ml}$ \\
\hline
\end{tabular}

Establishment of standard curve(Calibration curve) for UV visible spectroscopy method for analysis of Oxycodone hydrochloride in $0.1 \mathrm{~N} \mathrm{HCl}$.

100mg Oxycodone hydrochloride was dissolved in $5 \mathrm{ml}$ methanol and then diluted with $0.1 \mathrm{~N} \mathrm{HCl}$ upto $100 \mathrm{ml}$ to procedure stock solution $1000 \mu \mathrm{g} / \mathrm{ml}$. Preparation of stock solution 2:10 ml of stock 
1 solution was taken and diluted with $0.1 \mathrm{~N} \mathrm{HCl}$ upto $100 \mathrm{ml}$ to produce $100 \mu \mathrm{g} / \mathrm{ml}$ stock solution concentration.

Establishment of standard curve(Calibration curve) for UV visible spectroscopy method for analysis of Oxycodone hydrochloride in $0.1 \mathrm{~N} \mathrm{NaOH}$.

Weigh and powder 20 tablets. Weigh accurately a quantity of the powder containing about $0.15 \mathrm{gm}$ of Oxycodone hydrochloride add 50ml of $0.1 \mathrm{M} \mathrm{NaoH}$, dilute with $100 \mathrm{ml}$ of water, shake for 15 minutes and add sufficient water to produce $200 \mathrm{ml}$.Mix, filter and dilute $10 \mathrm{ml}$ of the filtrate to $100 \mathrm{ml}$ with water. To $10 \mathrm{ml}$ of the resulting solution add $10 \mathrm{ml}$ of $0.1 \mathrm{M} \mathrm{NaoH}$, dilute to $100 \mathrm{ml}$ with water and mix. Measure the absorbance of the resulting solution at the maximum at about $257 \mathrm{~nm}$.Calculate the content of Oxycodone hydrochloride taking 715 as the specific absorbance at $257 \mathrm{~nm}$.

Establishment of standard curve(Calibration curve) for UV visible spectroscopy method for analysis of Oxycodone hydrochloride in distilled water.

Preparation of stock solution 1:

100mg Oxycodone hydrochloride was dissolved in $5 \mathrm{ml}$ methanol and then diluted with distilled water upto $100 \mathrm{ml}$ to procedure stock solution $1000 \mathrm{mcg} / \mathrm{ml}$. Preparation of stock solution 2:10 ml of stock 1 solution was taken and diluted with distilled water upto $100 \mathrm{ml}$ to produce $100 \mu \mathrm{g} / \mathrm{ml}$ stock solution concentration.

Establishment of standard curve (Calibration curve) for UV visible spectroscopy method for analysis of Oxycodone hydrochloride in 6.8 phosphate buffers.

100mg Oxycodone hydrochloride was dissolved in 6.8 phosphate buffer upto $100 \mathrm{ml}$ to procedure stock solution. $1000 \mathrm{mcg} / \mathrm{ml}$. $10 \mathrm{ml}$ of stock 1 solution was taken and diluted with 6.8 phosphate buffer upto $100 \mathrm{ml}$ to produce $100 \mu \mathrm{g} / \mathrm{ml}$ stock solution concentration.

Establishment of standard curve (Calibration curve) for UV visible spectroscopy method for analysis of Oxycodone hydrochloride in $40 \%$ ethanol.

100mg Oxycodone hydrochloride was dissolved in $40 \%$ ethanol upto $100 \mathrm{ml}$ to procedure stock solution $1000 \mu \mathrm{g} / \mathrm{ml}$ l. Preparation of stock solution 2:10 $\mathrm{ml}$ of stock 1 solution was taken and diluted with $40 \%$ ethanol upto $100 \mathrm{ml}$ to produce $100 \mu \mathrm{g} / \mathrm{ml}$ stock solution concentrations.

Table 2: Values of Absorbance in different media

\begin{tabular}{|c|c|c|c|c|c|c|}
\hline \multirow[b]{2}{*}{$\begin{array}{l}\mathrm{Sr} \\
\text { no }\end{array}$} & \multirow{2}{*}{$\begin{array}{l}\text { Concentratio } \\
\mathrm{n} \\
(\mu \mathrm{g} / \mathrm{ml})\end{array}$} & \multicolumn{5}{|c|}{ Average. Absorbance } \\
\hline & & $0.1 \mathrm{~N} \mathrm{HCl}$ & $0.1 \mathrm{~N} N \mathrm{NaH}$ & $\begin{array}{l}\text { Distilled } \\
\text { water }\end{array}$ & $\begin{array}{l}40 \% \\
\text { ethanol }\end{array}$ & $\begin{array}{l}6.8 \text { phosphate } \\
\text { buffer }\end{array}$ \\
\hline 0 & 0 & 0 & 0 & 0 & 0 & 0 \\
\hline 1 & 5 & 0.296167 & 0.368767 & 0.358667 & 0.468967 & 0.389867 \\
\hline \multicolumn{2}{|c|}{143} & & & & & www.ajptr.com \\
\hline
\end{tabular}




\begin{tabular}{lllllll}
\hline 2 & 10 & 0.649167 & 0.742867 & 0.639867 & 0.8994 & 0.702633 \\
3 & 15 & 0.9936 & 1.082833 & 0.9596 & 1.309 & 1.024 \\
4 & 20 & 1.314033 & 1.4061 & 1.289133 & 1.721733 & \\
\hline
\end{tabular}

Table 3: Regression parameters

\begin{tabular}{|c|c|c|c|c|c|}
\hline \multirow{2}{*}{$\begin{array}{l}\text { Regression } \\
\text { parameters }\end{array}$} & \multicolumn{5}{|l|}{ Values } \\
\hline & $\begin{array}{l}0.1 \mathrm{~N} \\
\mathrm{HCl}\end{array}$ & $\begin{array}{l}0.1 \mathrm{~N} \\
\mathrm{NaOH}\end{array}$ & $\begin{array}{l}\text { Distilled } \\
\text { water }\end{array}$ & $\begin{array}{l}40 \% \\
\text { ethanol }\end{array}$ & $\begin{array}{l}6.8 \text { phosphate } \\
\text { buffer }\end{array}$ \\
\hline $\begin{array}{l}\text { Correlation co } \\
\text { efficient }\end{array}$ & 0.9993 & 0.999 & 0.998 & 0.9992 & 0.9973 \\
\hline Intercept & -0.0145 & 0.0148 & 0.0136 & 0.0232 & 0.0214 \\
\hline Slope & 0.0665 & 0.0705 & 0.0636 & 0.0856 & 0.0677 \\
\hline
\end{tabular}

\section{Assay}

Weigh and powder 20 tablets. Take a quantity of the powder equivalent to $0.15 \mathrm{~g}$ of Oxycodone hydrochloride

20 tablets $* 0.5 \mathrm{~g}$ Oxycodone hydrochloride $\rightarrow$ wt $\quad 0.15 \mathrm{~g}$

Oxycodone hydrochloride $\rightarrow \mathrm{X}$

Place in a volumetric flask (200ml) Add $50 \mathrm{ml} 0.1 \mathrm{M} \mathrm{NaOH}$ (using a burette).Dilute with $100 \mathrm{ml}$ of water, shake for 15 minutes, and add sufficient water to produce $200 \mathrm{ml}$. Mix, and filter. Dilute $10 \mathrm{ml}$ of the filtrate to $100 \mathrm{ml}$ with water (in a volumetric flask $100 \mathrm{ml}$ ). Add $10 \mathrm{ml}$ of the resulting solution to $10 \mathrm{ml}$ of $0.1 \mathrm{M} \mathrm{NaOH}$, dilute to $100 \mathrm{ml}$ with water (in a volumetric flask 100ml) . Measure the absorbance of the resulting solution at $\lambda \max =257 \mathrm{~nm}$ taking 0.715 as the value of $\mathrm{E}_{1 \%}$.

Blank: take $20 \mathrm{ml}$ of $0.1 \mathrm{M} \mathrm{NaOH}$ and complete to $100 \mathrm{ml}$ with water

Limit: Content: $95-105 \%$ of the prescribed (labeled)

\section{Experimental Work:}

\section{Preliminary trials}

The aim of the presented work was to develop extended release pellet formulation and release retardant formulation. For that multiple formulation and process parameter were studied. Drug concentration selected based upon the dose. The amount of MCC sphere was kept constant 300gm per batch based upon the capacity of Granurex machine. Amount of talc was kept constant usually it was used in the range of $1-10 \%$.

\section{Table 4: Preliminary trial batches}

\begin{tabular}{llllll}
\hline \multicolumn{8}{l}{ Batch size 3000 capsules } \\
\cline { 2 - 6 } Batch & DS 1 & DS 2 & DS 3 & DS 4 & DS 5
\end{tabular}




\begin{tabular}{lllllllllll} 
Drug layered & mg & gm & mg & gm & mg & gm & mg & gm & mg & gm \\
\hline MCC Sphere(30-35 mesh) & 100 & 300 & 100 & 300 & 100 & 300 & 100 & 300 & 100 & 300 \\
Oxycodone hydrochloride & 100 & 300 & 100 & 300 & 50 & 150 & 100 & 300 & 100 & 300 \\
Carbopol 974P NF & 10 & 30 & 60 & 180 & 80 & 240 & 50 & 150 & 60 & 180 \\
Talc & 10 & 30 & 10 & 30 & 10 & 30 & 10 & 30 & 10 & 30 \\
Aerosil & 5 & 15 & 5 & 15 & 5 & 15 & 5 & 15 & 5 & 15 \\
\hline
\end{tabular}

Effect of amount of Carbopol 974P NF

Carbopol 974P NF was used to increase the viscosity of the pellets. At certain level they increase the hardness of the pellets. When we increase the level of carbopol to $240 \mathrm{mg}$, it shows uneven shaped particle. This was observed because viscosity was increased too high.

During formulation of batch 1 and batch 2, it was observed that pellets are formed by batch 1 was crushable and from batch 2 was harder than batch 1 . In batch 3, it was observed that $240 \mathrm{mg}$ of carbopol 974P NF was enough to make hard pellets but uneven shape pellets were observed. It was observed that ethyl cellulose and white wax were factors which affect hardness of the pellets.

\section{Effect of concentration of binder:}

Ethyl cellulose taken as binder and different percentage of ethyl cellulose $45 \mathrm{cps}$ was studied. The viscosity of ethyl cellulose 45 cps was found to be $42-48$ centipoises. It was observed that when we increase the concentration of ethyl cellulose $45 \mathrm{cps}$ the shape of the pellets were changed.

\section{Table 5: Effect of concentration of binder}

\begin{tabular}{lllllllllll}
\hline Batch & DS 1 & \multicolumn{3}{c}{ DS 2 } & \multicolumn{3}{c}{ DS 3 } & \multicolumn{2}{c}{ DS 4 } & \multicolumn{2}{c}{ DS 5 } \\
Binder & mg & gm & mg & gm & mg & gm & mg & gm & mg & gm \\
\hline EC 45 cps & 10 & 30 & 10 & 30 & 20 & 60 & 10 & 30 & 10 & 30 \\
White wax & 5 & 15 & 5 & 15 & 15 & 45 & 5 & 15 & 5 & 15 \\
Isopropyl alcohol & qs & 1080 & qs & 1080 & qs & 2520 & qs & 1080 & qs & 1080 \\
\hline
\end{tabular}

Table 6: Evaluation of trial batches

\begin{tabular}{lll}
\hline Batch number & Pellets strength & Shape of pellets \\
\hline DS 1 & hard & Round \\
DS 2 & hard & Round \\
DS 3 & soft & Star Shape \\
DS 4 & hard & Round \\
DS 5 & hard & Round \\
\hline
\end{tabular}

From above trial it was concluded that batch 3 with 60mg of ethyl cellulose $45 \mathrm{cps}$ concentration was not enough to make hard pellets. Batch 1,2,4, and 5 with $30 \mathrm{mg}$ of concentration were shows good strength to the pellets and shows a round shape pellets.

\section{Effect of peristaltic pump and flow rate:}

Table 7: Effect of ethyl cellulose and white wax in trial batches:

\begin{tabular}{|c|c|c|c|c|c|}
\hline Batch & DS 1 & DS 2 & DS 3 & DS 4 & DS 5 \\
\hline Binder & mg gm & mg & mg & mg & mg \\
\hline
\end{tabular}




\begin{tabular}{lllllllllll}
\hline EC 45 cps & 10 & 30 & 10 & 30 & 20 & 60 & 10 & 30 & 10 & 30 \\
White wax & 5 & 15 & 5 & 15 & 15 & 45 & 5 & 15 & 5 & 15 \\
Isopropyl alcohol & qs & 1080 & qs & 1080 & qs & 2520 & qs & 1080 & Qs & 1080 \\
\hline
\end{tabular}

Flow rate of binder solution by peristaltic pump:

Table 8: Effect of Peristaltic pump in trail batches

\section{Evaluation of shape:}

\begin{tabular}{llllll}
\hline Flow rate & $1 \mathrm{ml} / \mathrm{min}$ & $1 \mathrm{ml} / \mathrm{min}$ & $3 \mathrm{ml} / \mathrm{min}$ & $1 \mathrm{ml} / \mathrm{min}$ & $1 \mathrm{ml} / \mathrm{min}$ \\
\hline
\end{tabular}

Table 9: Effect of peristaltic pump and flow rate in shape of the particles

\begin{tabular}{ll}
\hline Batch number & Shape of the pellets \\
\hline 1 & Round \\
2 & Round \\
3 & Star \\
4 & Round \\
5 & Round \\
\hline
\end{tabular}

As flow rate was increased from $1 \mathrm{ml} / \mathrm{min}$ to $3 \mathrm{ml} / \mathrm{min}$ shape of the pellets becomes change(star shaped) So, flow rate $1 \mathrm{ml} / \mathrm{min}$ required for pellets formation.

\section{Dissolution studies of trial batches:}

\section{Dissolution study data of trial Batches:}

\section{Drug release study of trial batch DS 1}

A dissolution study of batch 1 was performed in 0.1N HCL. Dissolution of drug layered pellets.

Condition- Media -900ml volume of 0.1N HCl, RPM-100, Apparatus-USP type 2(paddle)

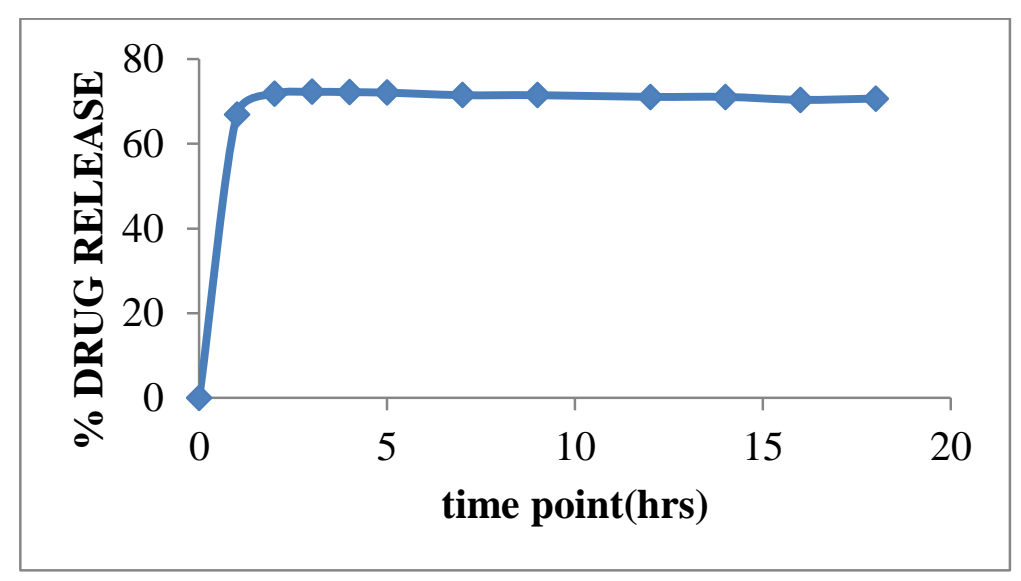

Figure 1: Graphical representation of dissolution data of batch DS 1

According to graph and dissolution data we concluded that more than $60 \%$ of drug was released in around $2 \mathrm{hrs}$ for intact drug layered pellets. According to data pellets does not show abuse deterrent or release retardant properties, So we did not performs drug release studies with crushed pellets.

\section{Drug release study for trial batch DS 2:}


Drug release study of batch 2 was performed in $0.1 \mathrm{~N} \mathrm{HCl}$ and 6.8 phosphate buffer. Drug release study in $0.1 \mathrm{~N} \mathrm{HCl}$ for intact and crushed pellets

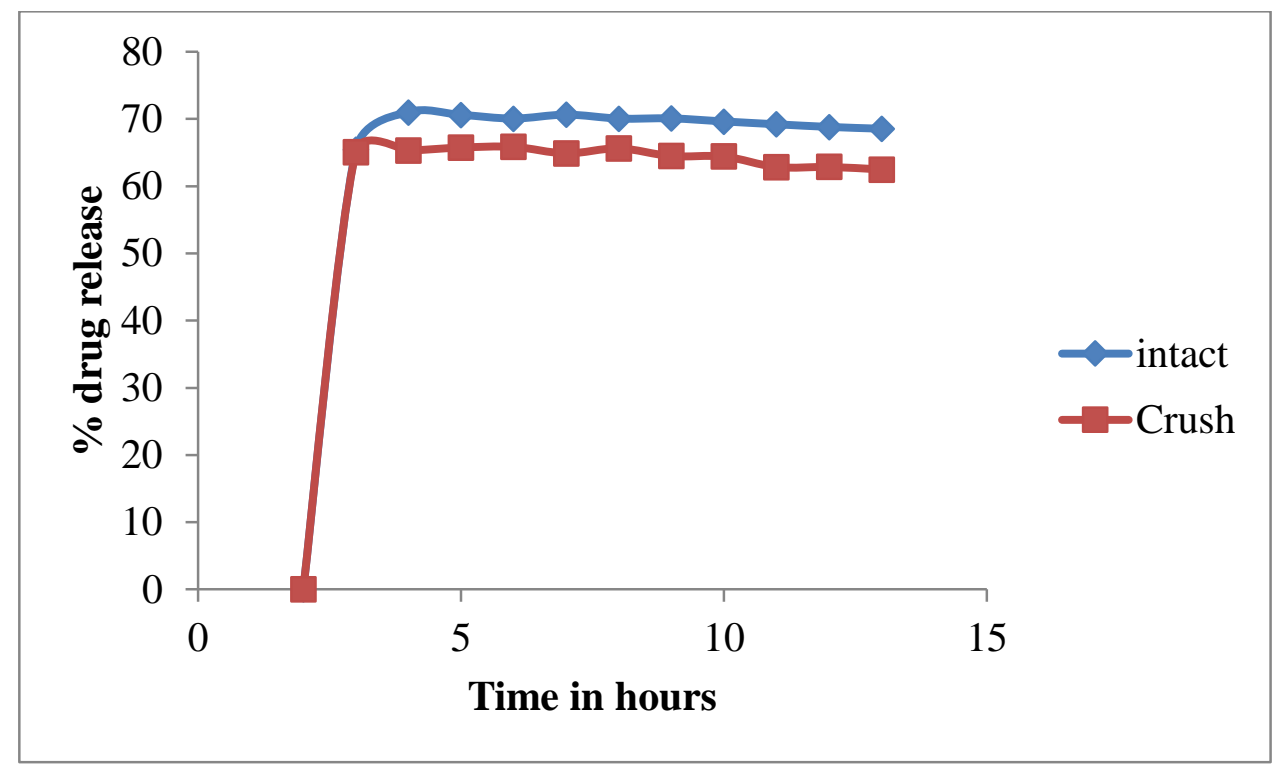

Figure 2: Graphical representation of dissolution data of batch DS 2 in $0.1 \mathrm{~N} \mathrm{HCl}$

According to the data, it was concluded that there are not large difference between the crushed pellets and intact pellets. Graph also shows that above $60 \%$ of drug was release within 3 hrs. So, they dose not retard the release rate.

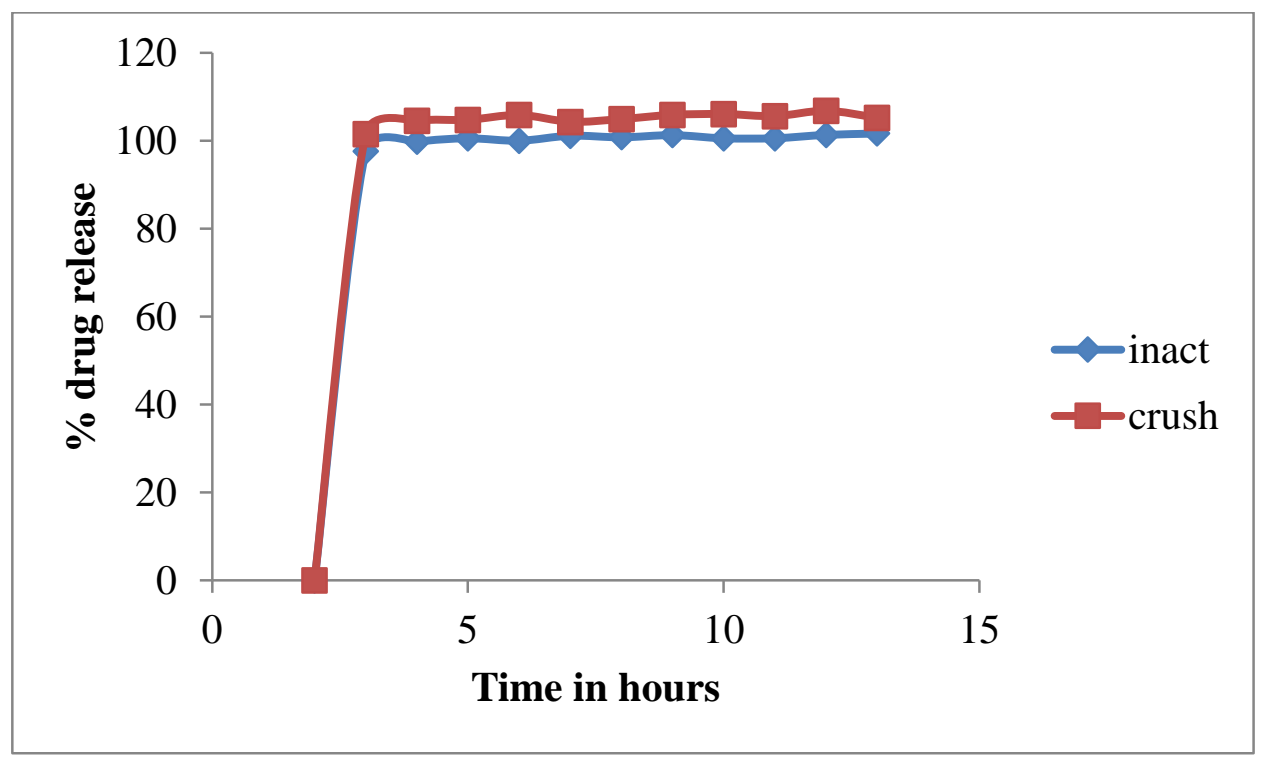

Figure 3: Graphical representation of drug release study of DS2 batch in 6.8 phosphate buffer

According to the data, it was concluded that there are not large difference between the crushed pellets and intact pellets. Graph also shows that around $100 \%$ of drug was release within 3 hrs. So, they dose not retard the release rate. 


\section{Drug release study of trial batch DS 3:}

Drug release study was performed in $0.1 \mathrm{~N} \mathrm{HCl}$

Table 10: Dissolution of intact pellets of trial batch DS 3 in $0.1 \mathrm{~N} \mathrm{HCl}$

\begin{tabular}{lll}
\hline Time (Hrs) & Intact pellets & Crushed pellets \\
\hline 0 & 0 & 0
\end{tabular}

Data shows that around $\frac{1}{100 \% \text { of drug was release within } 1 \text { hrs. So, they dose not retard the release }}$ rate. Therefore, further studies in different time points were not preformed.

\section{Drug release study of batch DS 4:}

Table 11: Dissolution of intact pellets of trial batch DS 4 in $0.1 \mathrm{~N} \mathrm{HCl}$

\begin{tabular}{lll}
\hline Time (Hrs) & Intact pellets & Crushed pellets \\
\hline 0 & 0 & 0 \\
1 & 91.8 & 96.1 \\
2 & 94.3 & 95.4 \\
3 & 95.1 & 96.4 \\
\hline
\end{tabular}

Data shows that around $95 \%$ of drug was release within 3 hrs. So, they dose not retard the release rate. Therefore, further studies in different time points were not be performed.

\section{Drug release study of trial batch DS 5:}

A drug release study was performed in $0.1 \mathrm{~N} \mathrm{HCl}$.

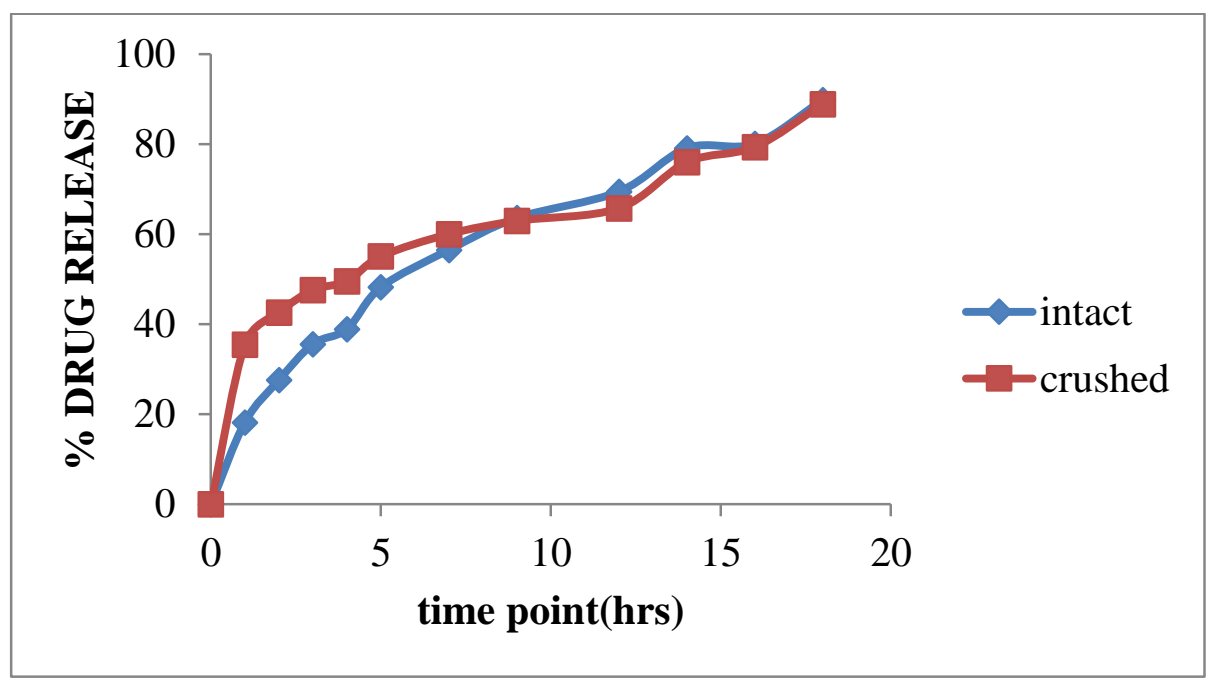

Figure 4: Graphical representation of batch DS 5:

According to the data it was shows that there are steady increase in the drug release with respect to the time. No rapid release in drug in earlier time points. According to this data batch DS 5 was taken as center point in design of experiment studies.

Table 12: Formula for extended release coating of drug layered pellets

\begin{tabular}{lll}
\hline Extended release coating & $\mathrm{Mg} /$ capsule & $\mathrm{Gm} / \mathrm{batch}$ \\
Cellulose acetate (CA-398-10) & 0.0228 & 68.4 \\
\hline
\end{tabular}




\begin{tabular}{lll}
\hline Polyethylene glycol3350 & 0.0012 & 3.6 \\
Acetone: Water(95:5) & & $1299.6: 68.4$ \\
Total wt & 336 & 347 \\
\hline
\end{tabular}

Drug release study of ER coated tablet in $0.1 \mathrm{~N} \mathrm{HCl}$.

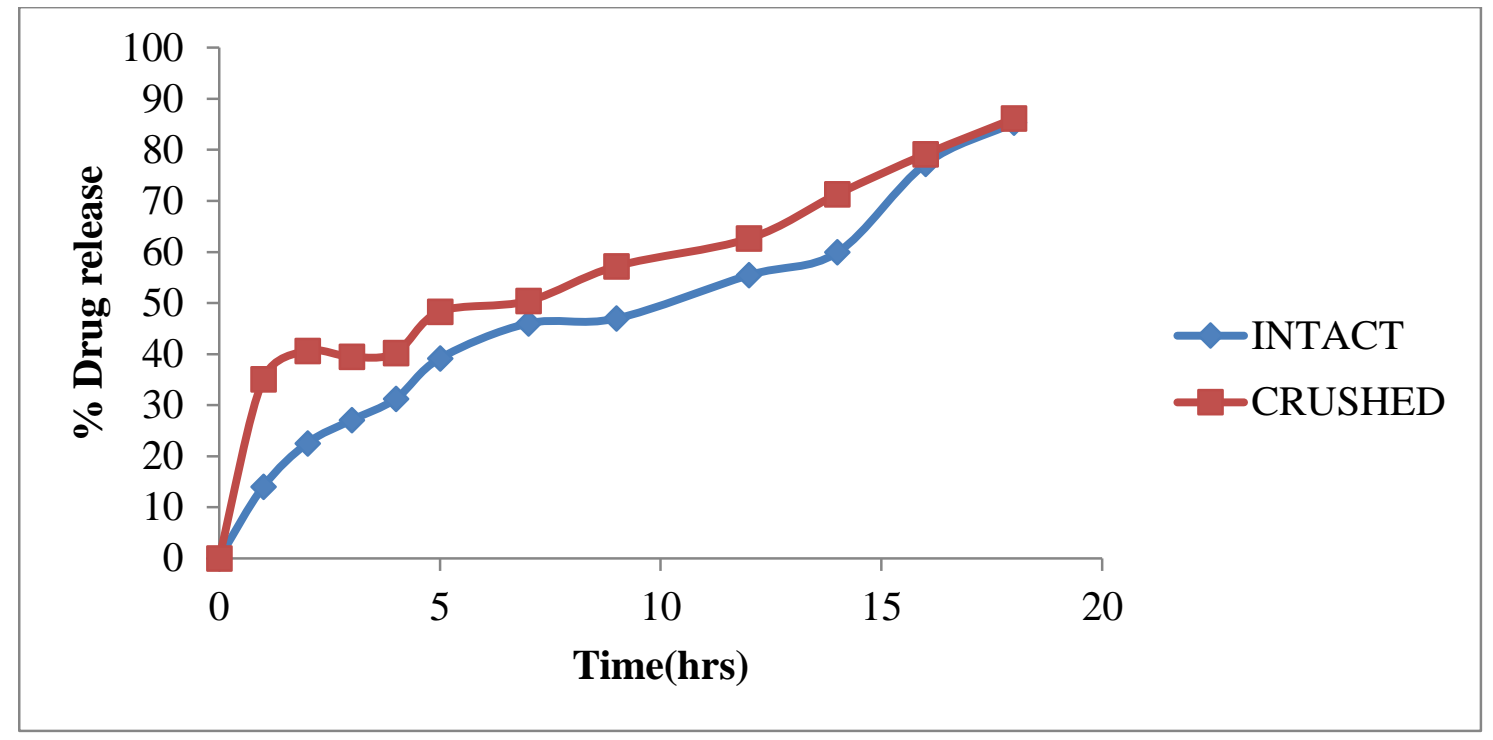

Figure 5: Graphical representation of drug release study of trial batch DS 5

According to the data it was shows that there is steady increase in the drug release with respect to the time. No rapid release in drug in earlier time points when ER coating

\section{$3^{2}$ Full factorial design}

A full factorial design is the one of the process in which we can determine the causes between the process and output of the process variable. We can measure the relationships between the dependent variable which can affect the independent variable. So, we sets input variables to gets optimize output results. From the preliminary trial was observed that concentration of carbopol has effect in $\%$ drug release.

Response factors include:

\section{i.Crushability}

ii.Loss on drying

iii.LOD after drying

iv.Percentage assay

Design of experiment batches data with actual value and response.

Table 13: Full factorial design batches

\begin{tabular}{llll}
\hline Design batches & \multicolumn{2}{c}{ Changes(mg/units) } & \\
& Carbopol(mg) & $\begin{array}{l}\text { Ethyl cellulose } \\
\mathbf{4 5} \text { cPs (mg) }\end{array}$ & White Wax(mg) \\
\hline PC 1 & 40 & 20 & 10 \\
\hline
\end{tabular}




\begin{tabular}{llll}
\hline PC 2 & 40 & 20 & 3 \\
PC3 & 40 & 8 & 10 \\
PC 4 & 70 & 8 & 3 \\
PC 5 & 70 & 20 & 10 \\
PC 6 & 70 & 20 & 3 \\
PC 7 & 40 & 8 & 3 \\
PC 8 & 55 & 14 & 6.5 \\
PC 9 & 55 & 12 & 4.5
\end{tabular}

Response of design batches.

Table 14: Responses of these design batches

\begin{tabular}{|c|c|c|c|c|c|}
\hline \multicolumn{2}{|l|}{ Crusibility } & \multirow{2}{*}{$\begin{array}{l}\text { Loss on } \\
\text { drying } \\
105^{\circ} \mathrm{C} \text { for } \\
10 \mathrm{~min}\end{array}$} & \multirow{2}{*}{$\begin{array}{l}\text { LOD after } \\
\text { drying } \\
40^{\circ} \mathrm{C} \text { for } 24 \\
\text { hrs }\end{array}$} & \multicolumn{2}{|l|}{ \% Assay } \\
\hline $\begin{array}{l}\text { Average of } 5 \\
\text { pellets }\end{array}$ & $\begin{array}{l}\text { Standard } \\
\text { deviation }\end{array}$ & & & $\mathrm{N}=1$ & $\mathrm{~N}=3$ \\
\hline 0.96 & 0.193 & $4.40 \%$ & $3.40 \%$ & $95.27 \%$ & $93.52 \%$ \\
\hline 0.992 & 0.25 & $4.61 \%$ & $2.61 \%$ & $96.66 \%$ & $94.63 \%$ \\
\hline 0.781 & 0.235 & $6.40 \%$ & $5.54 \%$ & $91.52 \%$ & $94.77 \%$ \\
\hline 0.58 & 0.065 & $8.55 \%$ & $5.67 \%$ & $96.38 \%$ & $95.37 \%$ \\
\hline 0.841 & 0.085 & $6.70 \%$ & $4.81 \%$ & $101.95 \%$ & $98.94 \%$ \\
\hline 1.143 & 0.117 & $3.12 \%$ & $2.12 \%$ & $96.11 \%$ & $93.27 \%$ \\
\hline 0.845 & 0.223 & $0.97 \%$ & $0.88 \%$ & $96.94 \%$ & $92.44 \%$ \\
\hline 1.26 & 0.138 & $9.83 \%$ & $5.66 \%$ & $103.33 \%$ & $98.56 \%$ \\
\hline 0.99 & 0.101 & $2.21 \%$ & $4.01 \%$ & $98 \%$ & $98.30 \%$ \\
\hline
\end{tabular}

Crushing strength of design batch PC 1

\section{Ta.Mplus Stable Micro Systems}

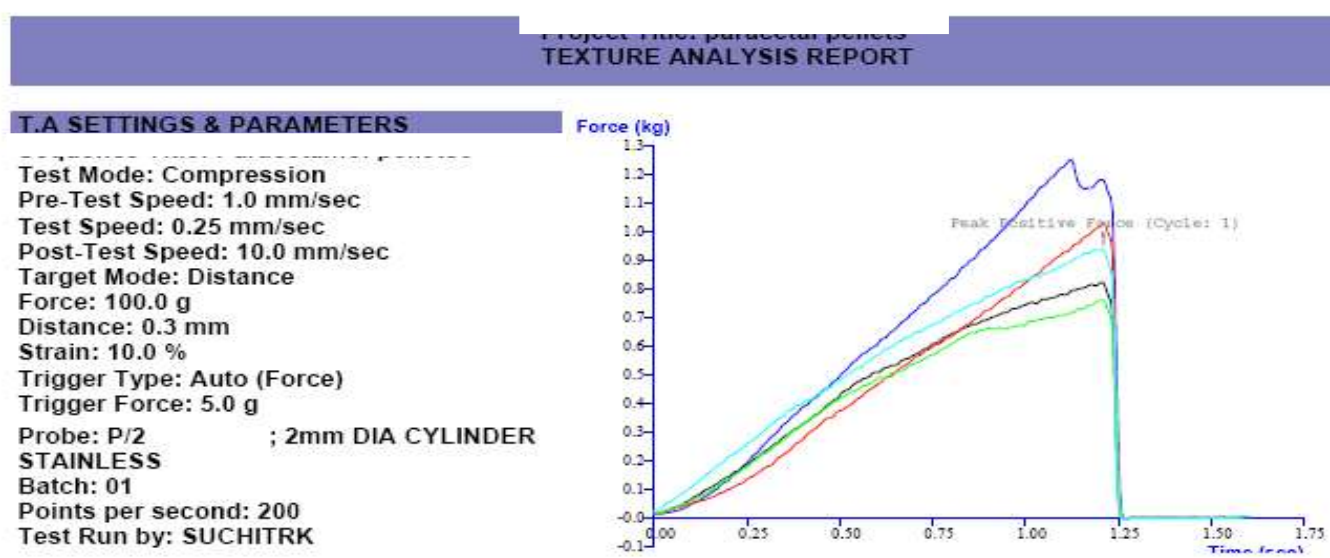

NOTES

This space is to enter notes regarding the test data. 


\section{taxpoplus Toxrure analyser \\ Stable Micro Systems

\begin{tabular}{|c|c|c|c|}
\hline \multicolumn{4}{|c|}{ RESULTS } \\
\hline Test 1D & Batch & & Peak Positive Force (Cycle: 1) \\
\hline & & & $\mathrm{kg}$ \\
\hline & & & Peak Positive Force (Cycle: 1) \\
\hline Start Batch 01 & 01 & & \\
\hline End Batch 01 & 01 & & \\
\hline Average: & $01(\mathrm{~F})$ & AVERAGE("BATCH") & 0.880 \\
\hline S.D. & $01(F)$ & STDEV("BATCH") & 0.183 \\
\hline Coef. of Variation & $01(F)$ & STDEV('BATCH")/ AVERAGE("BATCH') ' 100 & 20.085 \\
\hline End of Test Data & & & \\
\hline
\end{tabular}

Crushing strength of design batch PC 2

stable Micro Systems

TEX́TURE ANALYSIS REPORT

\section{T.A SETTINGS \& PARAMETERS}

Test Mode: Compression

Pre-Test Speed: $1.0 \mathrm{~mm} / \mathrm{sec}$

Test Speed: $0.25 \mathrm{~mm} / \mathrm{sec}$

Post-Test Speed: $10.0 \mathrm{~mm} / \mathrm{sec}$

Target Mode: Distance

Force: $100.0 \mathrm{~g}$

Distance: $0.3 \mathrm{~mm}$

Strain: $10.0 \%$

Trigger Type: Auto (Force)

Trigger Force: $5.0 \mathrm{~g}$

Probe: $P / 2$

$; 2$ mm DIA CYLINDER

STAINLESS

Batch: 02

Points per second: 200

Test Run by: SUCHITRK

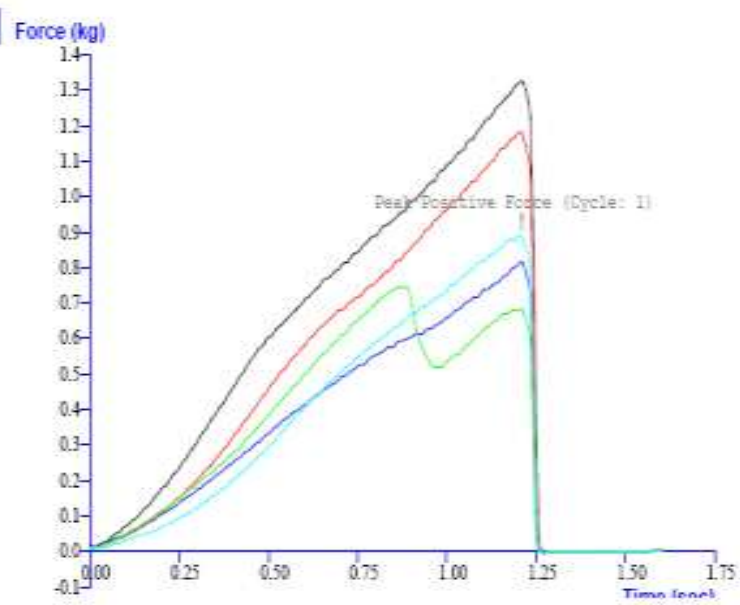

\section{NOTES}

This space is to enter notes regarding the test data 


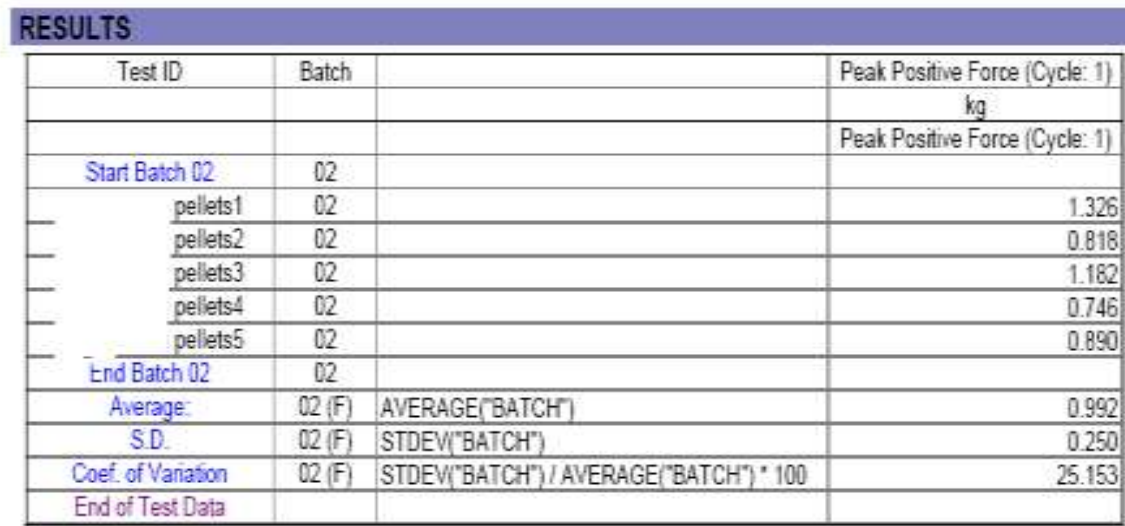

Crushability studies of design batch PC 3

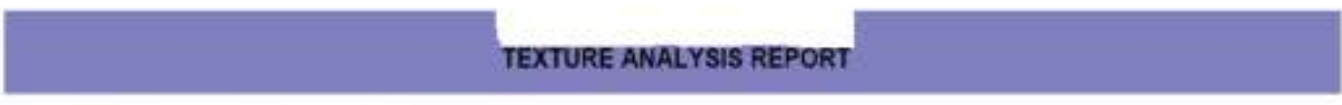

\section{T.A SEITINGS \& PARAMETERS}

Test Mode: Compression

Pre-Test Speed: $1.0 \mathrm{~mm} / \mathrm{sec}$

Test Speed: $0.25 \mathrm{~mm} / \mathrm{sec}$

Post-Test Speed: $10.0 \mathrm{~mm} / \mathrm{sec}$

Target Mode: Distance

Force: $100.0 \mathrm{~g}$

Distance: $0.3 \mathrm{~mm}$

Strain: $10.0 \%$

Trigger Type: Auto (Force)

Trigger Force: $5.0 \mathrm{~g}$

Probe: P/2

2mm DIA CYLINDER

STAINLESS

Batch: 03

Points per second: 200

Test Run by: SUCHITRK

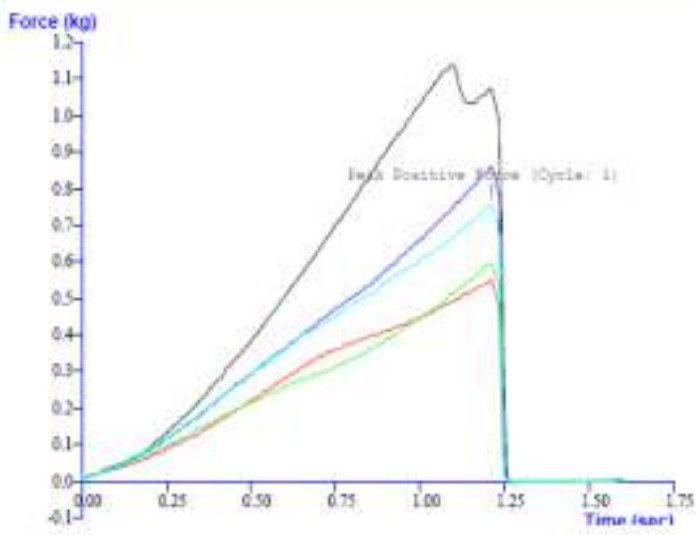

NOTES

This space is to enter notes regarding the test data. 


\section{RESULTS}

\begin{tabular}{|c|c|c|c|}
\hline Test ID & Batch & & Peak Positive Force (Cycle: 1) \\
\hline & & & $\mathrm{kg}$ \\
\hline & & & Peak Positive Force (Cycle: 1) \\
\hline Start Batch 03 & 03 & & \\
\hline peletels031 & 03 & & 1.138 \\
\hline peileis: 32 & 03 & & 0.861 \\
\hline peletis:33 & 03 & & 0.552 \\
\hline pelets:134 & 03 & & 0.596 \\
\hline pelets:355 & 03 & & 0.756 \\
\hline End Batch 03 & 03 & & \\
\hline Average: & $03\langle\mathrm{~F}\rangle$ & AVERAGE('BATCH') & 0.781 \\
\hline S.D. & $03|\mathrm{~F}\rangle$ & STDEV(BATCH'] & 0.235 \\
\hline Coefi. of Varafion & $03 / \mathrm{F}\rangle$ & STDEV(BATCH') IAVERAGE|"BATCH") * 100 & 30.130 \\
\hline End of Test Data & & & \\
\hline
\end{tabular}

Crushability of design batch PC 4

\section{TEXTURE ANALYSIS REPORT}

\section{TA SETINGS \& PARAMETERS}

Test Mode: Compression

Pre-Test Speed: $1.0 \mathrm{~mm} / \mathrm{sec}$

Test Speed: $0.25 \mathrm{~mm} / \mathrm{sec}$

Post-Test Speed: $10.0 \mathrm{~mm} / \mathrm{sec}$

Target Mode: Distance

Force: $100.0 \mathrm{~g}$

Distance: $0.3 \mathrm{~mm}$

Strain: $10.0 \%$

Trigger Type: Auto (Force)

Trigger Force: $5.0 \mathrm{~g}$

Probe: $P / 2$

STAINLESS

Batch: 04

Points per second: 200

Test Run by: SUCHITRK

;2mm DIA CYLINDER

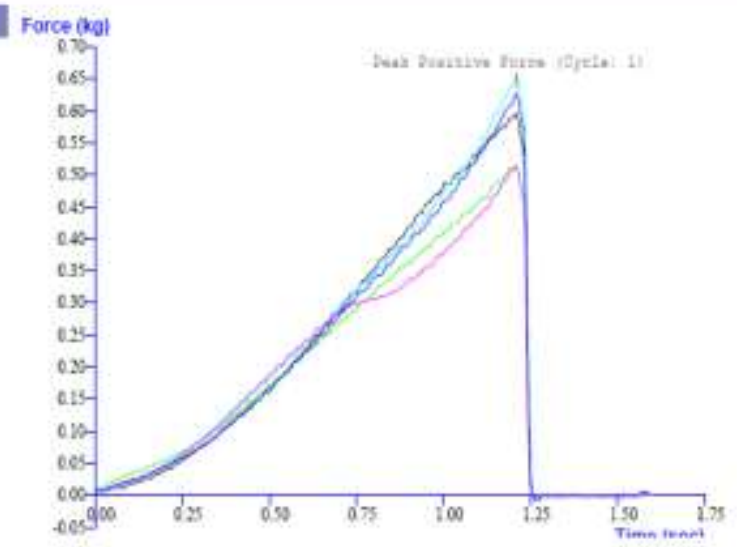

\section{NOTES}

This space is to enter notes regarding the test data. 


\begin{tabular}{|c|c|c|c|}
\hline \multicolumn{4}{|l|}{ RESULTS } \\
\hline Test ID & Batch & & Peak Positive Force (Oycle: 1) \\
\hline & & & kg \\
\hline & & & Peak Positive Force (Cycle: 1) \\
\hline Start Batch 04 & $\mathrm{OH}$ & & \\
\hline pellets0 & 04 & & 0.595 \\
\hline pelets1 & Q & & 0.627 \\
\hline pelets3 & 04 & & 0.511 \\
\hline pelets4 & 04 & & 0.654 \\
\hline pelets 5 & 04 & & 0.514 \\
\hline End Batch 04 & O4 & & \\
\hline Average: & $04(\mathrm{~F})$ & AVERAGE('BATCH') & 0.580 \\
\hline S.D. & $04(\mathrm{f})$ & STDEV('BATCH') & 0.065 \\
\hline Coef. of Vanation & $04(\mathrm{~F})$ & STDEV $\left({ }^{\prime} \text { BATCH" } / \text { AVERAGE/"BATCH" }\right)^{\prime}=100$ & 11253 \\
\hline End of Test Daia & & & \\
\hline
\end{tabular}

\section{Crushability of design batch PC 5}

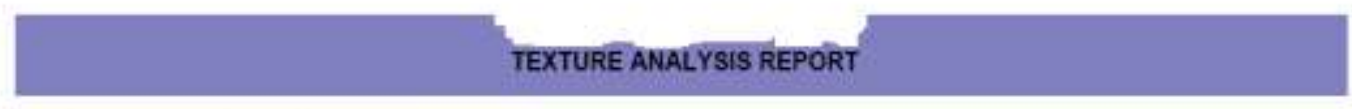

\section{T.A SETTINGS \& PARAMETERS}

Test Mode: Compression

Pre-Test Speed: $1.0 \mathrm{~mm} / \mathrm{sec}$

Test Speed: $0.25 \mathrm{~mm} / \mathrm{sec}$

Post-Test Speed: $10.0 \mathrm{~mm} / \mathrm{sec}$

Target Mode: Distance

Force: $100.0 \mathrm{~g}$

Distance: $0.3 \mathrm{~mm}$

Strain: $10.0 \%$

Trigger Type: Auto (Force)

Trigger Force: $5.0 \mathrm{~g}$

Probe: P/2

;2mm DIA CYLINDER

STAINLESS

Batch: 05

Points per second: 200

Test Run by: SUCHITRK

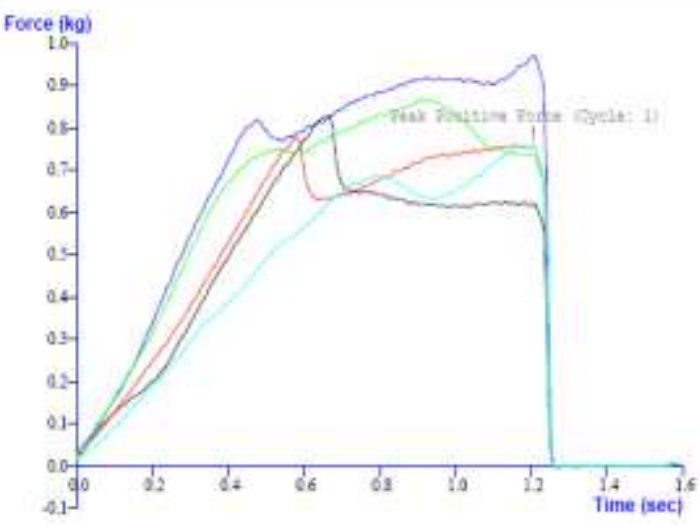

NOTES

This space is to enter notes regarding the test data 
RESULTS

\begin{tabular}{|c|c|c|c|}
\hline Test ID & Batch & & Peak Positive Force (Cycle: 1) \\
\hline & & & $\mathrm{kg}$ \\
\hline & & & Peak Positive Force (Cycle: 1) \\
\hline Start Batch 05 & 05 & & \\
\hline pellets 1 & 05 & & 0.828 \\
\hline pellets2 & 05 & & 0.971 \\
\hline pellets 3 & 05 & & 0.778 \\
\hline pellets4 & 05 & & 0.870 \\
\hline pellets 5 & 05 & & 0.758 \\
\hline End Batch 05 & 05 & & \\
\hline Averaye:- & $05(F)$ & AVERAGE["BATCH"] & 0.841 \\
\hline S.D. & $05(F)$ & STDEV('BATCH') & 0.085 \\
\hline Coel of Variaton & $05(\mathrm{~F})$ & STDEV("BATCH") / AVERAGE["BATCH") $* 100$ & 10.114 \\
\hline End of Test Data & & & \\
\hline
\end{tabular}

\section{Credibility study of design batch PC 6}

\section{2. vicplus}

\section{Stable Micro Systems}

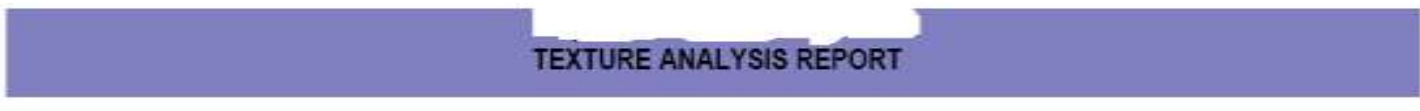

\section{T.A SETTINGS \& PARAMETERS}

Test Mode: Compression Pre-Test Speed: $1.0 \mathrm{~mm} / \mathrm{sec}$

Test Speed: $0.25 \mathrm{~mm} / \mathrm{sec}$

Post-Test Speed: $10.0 \mathrm{~mm} / \mathrm{sec}$

Target Mode: Distance

Force: $100.0 \mathrm{~g}$

Distance: $0.3 \mathrm{~mm}$

Strain: $10.0 \%$

Trigger Type: Auto (Force)

Trigger Force: $5.0 \mathrm{~g}$

Probe: $P / 2$

STAINLESS

Batch: 06

Points per second: 200

Test Run by: SUCHITRK

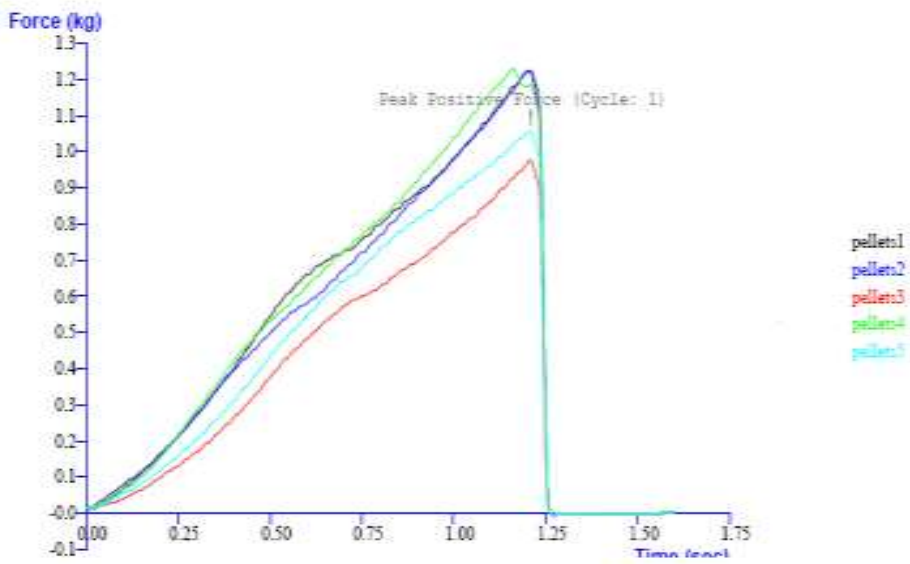

\section{NOTES}

This space is to enter notes regarding the test data. 


\section{RESULTS}

\begin{tabular}{|c|c|c|c|}
\hline Test ID & Batch & & Peak Positive Force (Cycle: 1) \\
\hline & & & $\mathrm{kg}$ \\
\hline & & & Peak Positive Force (Cycle: 1) \\
\hline Start Batch 06 & 06 & & \\
\hline pelets & 06 & & 1223 \\
\hline pelets: & 06 & & 1226 \\
\hline pelets. & 06 & & 0.979 \\
\hline peliets & 06 & & 1231 \\
\hline pelets & 06 & & 1.058 \\
\hline End Batch 06 & 06 & & \\
\hline Average: & $06(\mathrm{~F})$ & AVERAGE["BATCH") & 1.143 \\
\hline SD. & $06(\mathrm{~F})$ & STDEV/"BATCH') & 0.1 \\
\hline Coef. of Variation & $06(F)$ & STDEV/BATCH" $/$ /AVERAGE $\left(\right.$ BATCH $\left.^{*}\right) \cdot 100$ & 10275 \\
\hline End of Test Data & & & \\
\hline
\end{tabular}

\section{Crushability of design batch PC 7}

\section{TEXTURE ANALYSIS REPORT}

\section{I.A SETTINGS \& PARAMETERS}

Test Mode: Compression

Pre-Test Speed: $1.0 \mathrm{~mm} / \mathrm{sec}$

Test Speed: $0.25 \mathrm{~mm} / \mathrm{sec}$

Post-Test Speed: $10.0 \mathrm{~mm} / \mathrm{sec}$

Target Mode: Distance

Force: $100.0 \mathrm{~g}$

Distance: $0.3 \mathrm{~mm}$

Strain: $10.0 \%$

Trigger Type: Auto (Force)

Trigger Force: $5.0 \mathrm{~g}$

Probe: $\mathrm{P} / 2$; $\quad ; \mathrm{mm}$ DIA CYLINDER

STAINLESS

Batch: 07

Points per second: 200

Test Run by: SUCHITRK

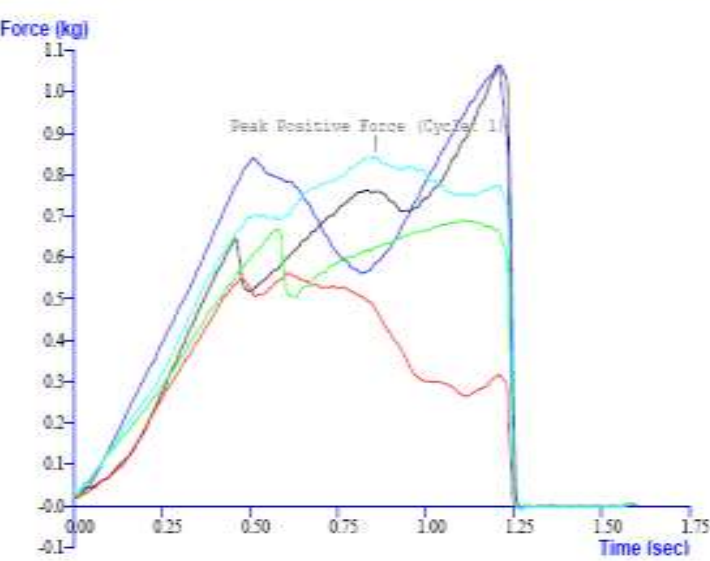

\section{NOTES}

This space is to enter notes regarding the test data 


\section{RESULTS}

\begin{tabular}{|c|c|c|c|}
\hline Test 10 & Batch & & Peak Posilive Force (Cycle; 1$)$ \\
\hline & & & $\mathrm{kg}$ \\
\hline & & & Peak Positive Force (Cycle: 1) \\
\hline Stat Batch 07 & 07 & & \\
\hline pelets 1 & 07 & & 1065 \\
\hline Jellets2 & 07 & & 1063 \\
\hline pejets 3 & 07 & & 0.563 \\
\hline peliets 4 & 07 & & 0.691 \\
\hline pelets5 & 07 & & 0.843 \\
\hline End Batch 07 & 07 & & \\
\hline Average: & $07(F)$ & AVERAGE[BATCH'] & 0.846 \\
\hline S.0. & $07(\mathrm{f})$ & STDEV(BATCH') & 0.223 \\
\hline Coefi col Variation & $07(\mathrm{~F})$ & STDEV(BATCH') / AVERAGE("BATCH') 100 & 26.416 \\
\hline End of Test Data & & & \\
\hline
\end{tabular}

Crushability study of design batch PC 8

\section{TEXTURE ANALYSIS REPORT}

\section{T.A SETTINGS \& PARAMETERS}

Test Mode: Compression

Pre-Test Speed: $1.0 \mathrm{~mm} / \mathrm{sec}$

Test Speed: $0.25 \mathrm{~mm} / \mathrm{sec}$

Post-Test Speed: $10.0 \mathrm{~mm} / \mathrm{sec}$

Target Mode: Distance

Force: $100.0 \mathrm{~g}$

Distance: $0.3 \mathrm{~mm}$

Strain: $10.0 \%$

Trigger Type: Auto (Force)

Trigger Force: $5.0 \mathrm{~g}$

Probe: P/2

STAINLESS

Batch: 08

Points per second: 200

Test Run by: SUCHITRK

; 2mm DIA CYLINDER

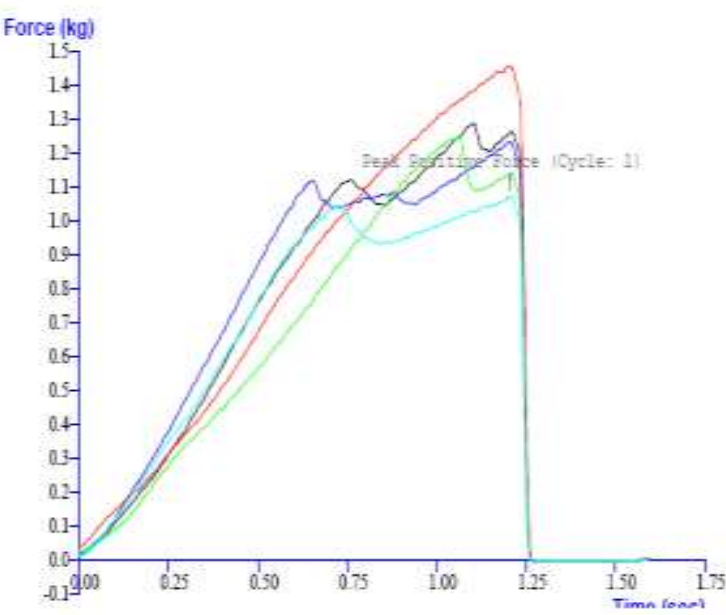

\section{NOTES}

This space is to enter notes regarding the test data. 


\begin{tabular}{|c|c|c|c|}
\hline \multicolumn{4}{|l|}{ RESULTS } \\
\hline Test ID & Batch & & Feak Postive Foros (Oyde: 1) \\
\hline & & & $\mathrm{kg}$ \\
\hline & & & Peak Positve Force (Orcie: 1$)$ \\
\hline Start Batch 08 & 06 & & \\
\hline pelets & 08 & & 1.288 \\
\hline peleters. & 06 & & 1.233 \\
\hline peliets & 08 & & 1.458 \\
\hline pelets & 08 & & 1.247 \\
\hline pelets. & 03 & & 1.072 \\
\hline End Batch 08 & 06 & & \\
\hline Average: & $08[F]$ & AVERAGE[BATCH"] & 1260 \\
\hline SO. & $0 B(F)$ & STDEV(BATCH) & 0.138 \\
\hline Coef. of Variation & $0 B[F]$ & STDEV/(BATCH)/AVERAGE(BATCH) $* 100$ & 10.942 \\
\hline End of Test Data & & & \\
\hline
\end{tabular}

Particle size studies were performed for these design batches and we got precise $D 90$ values in batch PC 4 and batch PC 6. 


\begin{tabular}{|c|c|c|c|c|c|c|c|}
\hline $\begin{array}{l}\text { Company: } \\
\text { User: } \\
\text { Result file: } \\
\text { Task file: } \\
\text { Time: }\end{array}$ & \multicolumn{7}{|c|}{$\begin{array}{l}\text { Retsch Technology } \\
\text { formulation2 } \\
\text { C.1Solution111CAMDATPCMPCM_ER } 4001 \text {.rdf } \\
\text { C.1Solution11/CAMSYSPCM.afg } \\
11 / 22 / 2017,17: 15 \text {, duration } 0 \text { min } 17 \text { s at } 1.0 \% \text { covered area, in }\end{array}$} \\
\hline $\begin{array}{l}\text { Particle model: } \\
\text { No. of particles: } \\
\text { Fitting: }\end{array}$ & \multicolumn{7}{|c|}{$\begin{array}{l}x \mathrm{x} \text { min } \\
\mathrm{C} \overline{\mathrm{C}} \mathrm{D}-\mathrm{B}-5523, \mathrm{CCD}-\mathrm{Z}-721 \\
\text { no }\end{array}$} \\
\hline \multicolumn{8}{|l|}{ Material: } \\
\hline Size class & {$[\mathrm{mm}]$} & p3 $[\%]$ & Q3 [\%] & SPHT3 & Symm3 & $\mathrm{b} / 13$ & PDN \\
\hline $\begin{array}{c}0.160 \\
0.250 \\
0.400 \\
0.630 \\
1.000 \\
1.600 \\
2.500 \\
4.000 \\
6.300 \\
>10.000\end{array}$ & $\begin{array}{c}<0.160 \\
0.250 \\
0.400 \\
0.630 \\
1.000 \\
1.600 \\
2.500 \\
4.000 \\
6.300 \\
10.000\end{array}$ & $\begin{array}{c}0.00 \\
0.00 \\
0.01 \\
0.30 \\
23.96 \\
72.15 \\
3.58 \\
0.00 \\
0.00 \\
0.00 \\
0.00\end{array}$ & $\begin{array}{l}0.00 \\
0.00 \\
0.01 \\
0.31 \\
24.27 \\
96.42 \\
100.00 \\
100.00 \\
100.00 \\
100.00 \\
100.00\end{array}$ & $\begin{array}{l}0.854 \\
0.940 \\
0.945 \\
0.914 \\
0.958 \\
0.896 \\
0.729\end{array}$ & $\begin{array}{l}0.859 \\
0.914 \\
0.956 \\
0.929 \\
0.937 \\
0.905 \\
0.756\end{array}$ & $\begin{array}{l}0.793 \\
0.827 \\
0.726 \\
0.789 \\
0.904 \\
0.812 \\
0.804\end{array}$ & $\begin{array}{c}612 \\
8 \\
11 \\
132 \\
1832 \\
3245 \\
40 \\
0 \\
0 \\
0 \\
0\end{array}$ \\
\hline
\end{tabular}

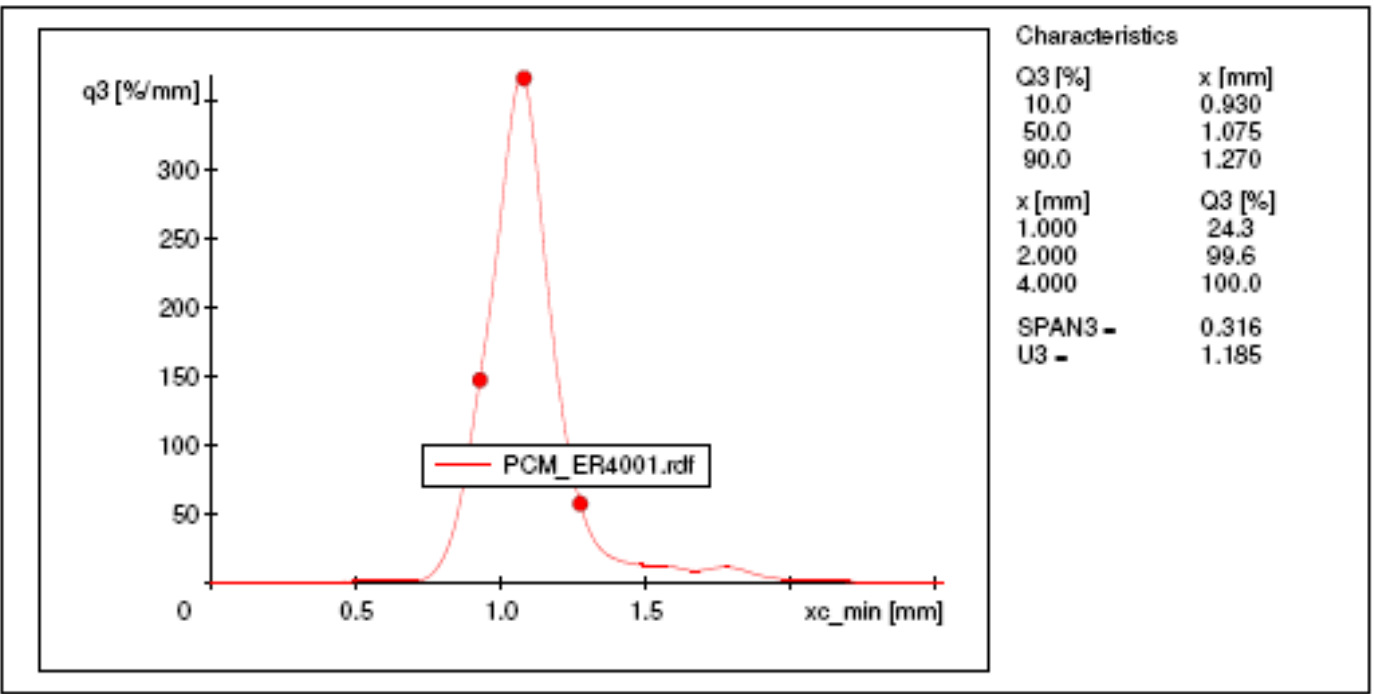

Particle size of Design batch PC 6 


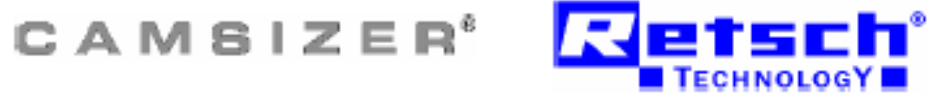

\begin{tabular}{|c|c|c|c|c|c|c|c|}
\hline $\begin{array}{l}\text { Company: } \\
\text { User: } \\
\text { Result file: } \\
\text { Task file: } \\
\text { Time: }\end{array}$ & \multicolumn{7}{|c|}{ 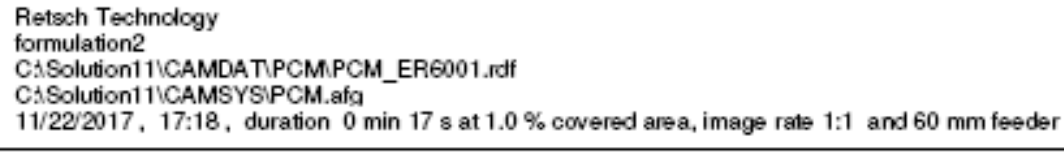 } \\
\hline $\begin{array}{l}\text { Particle model: } \\
\text { No. of particles: } \\
\text { Fitting: }\end{array}$ & \multicolumn{7}{|c|}{$\begin{array}{l}\text { xc-min } \\
\text { CC } \mathrm{CD}-\mathrm{B}-2671, \mathrm{CCD}-\mathrm{Z}=262 \\
\text { no }\end{array}$} \\
\hline \multicolumn{8}{|l|}{ Material: } \\
\hline Size class & {$[\mathrm{mm}]$} & $p 3[\%]$ & $03[\%]$ & SPHT3 & Symm3 & $b / 13$ & PDN \\
\hline $\begin{array}{c}0.160 \\
0.250 \\
0.400 \\
0.630 \\
1.000 \\
1.600 \\
2.500 \\
4.000 \\
6.300 \\
>10.000\end{array}$ & $\begin{array}{c}<0.160 \\
0.250 \\
0.400 \\
0.630 \\
1.000 \\
1.600 \\
2.500 \\
4.000 \\
6.300 \\
10.000\end{array}$ & $\begin{array}{c}0.00 \\
0.01 \\
0.09 \\
0.03 \\
15.84 \\
71.15 \\
12.88 \\
0.00 \\
0.00 \\
0.00 \\
0.00\end{array}$ & $\begin{array}{l}0.00 \\
0.01 \\
0.10 \\
0.13 \\
15.97 \\
87.12 \\
100.00 \\
100.00 \\
100.00 \\
100.00 \\
100.00\end{array}$ & $\begin{array}{l}0.859 \\
0.909 \\
0.910 \\
0.918 \\
0.949 \\
0.818 \\
0.661\end{array}$ & $\begin{array}{l}0.827 \\
0.820 \\
0.913 \\
0.947 \\
0.935 \\
0.856 \\
0.726\end{array}$ & $\begin{array}{l}0.753 \\
0.768 \\
0.770 \\
0.731 \\
0.892 \\
0.711 \\
0.723\end{array}$ & $\begin{array}{c}144 \\
19 \\
96 \\
10 \\
665 \\
1632 \\
82 \\
0 \\
0 \\
0 \\
0\end{array}$ \\
\hline
\end{tabular}

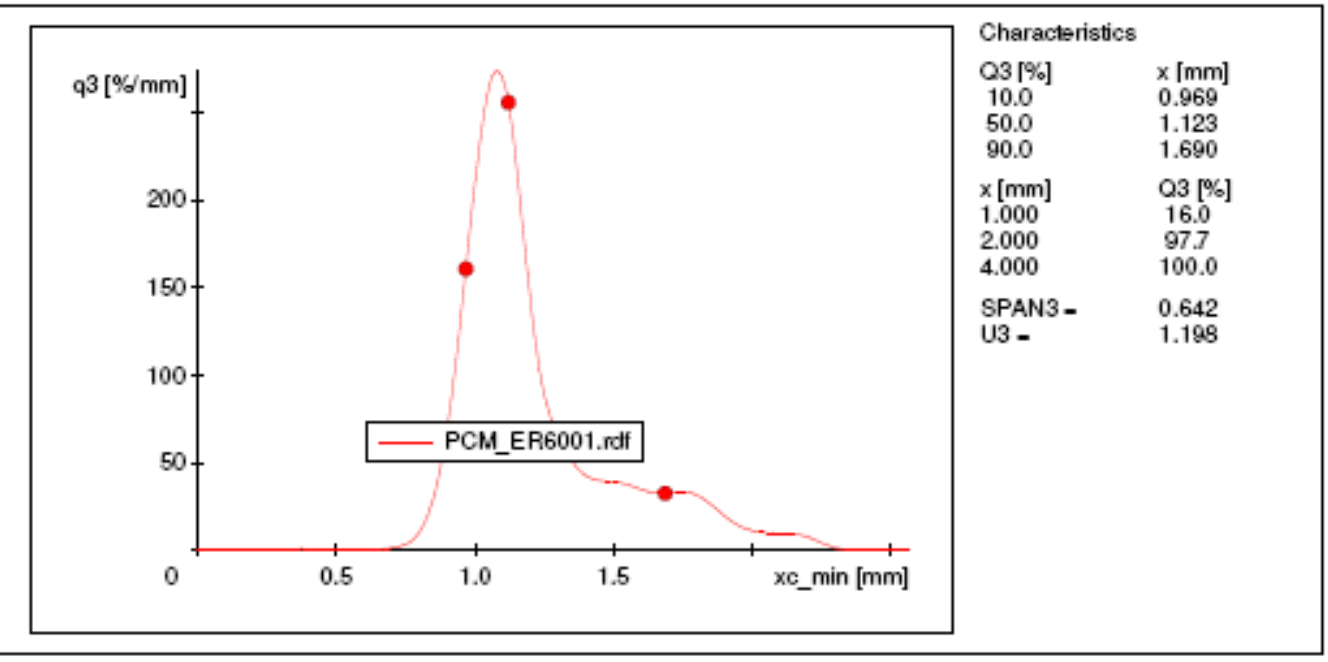

Factors to be set on making drug layered pellet on Granurex of Design batch PC 1 to batch PC 8

\section{Batch PC 1}

Table 15: Process parameter for design batch PC 1 in granurex technology

\begin{tabular}{|l|l|l|l|l|l|l|l|}
\hline Time & $\begin{array}{l}\text { Slit air } \\
\text { Temp. }\left({ }^{\circ} \mathbf{C}\right)\end{array}$ & $\begin{array}{l}\text { Slit air } \\
\text { volume }\end{array}$ & $\begin{array}{l}\text { Disc } \\
\text { RPM }\end{array}$ & $\begin{array}{l}\text { Product } \\
\text { temp }\end{array}$ & $\begin{array}{l}\text { Spray } \\
\text { rate(RPM) }\end{array}$ & $\begin{array}{l}\text { Feed } \\
\text { rate(rpm) }\end{array}$ & $\begin{array}{l}\text { Chamber } \\
\text { statics }\end{array}$ \\
\hline 10 & 35 & 0.11 & 377 & 20.9 & 3 & 1 & -0.1 \\
\hline 30 & 35 & 0.11 & 377 & 19.3 & 3 & 2 & -0.2 \\
\hline 50 & 35 & 0.11 & 448 & 19.2 & 2.6 & 2 & -0.3 \\
\hline 70 & 35 & 0.11 & 448 & 19.1 & 2.8 & 2 & -0.2 \\
\hline 90 & 35 & 0.11 & 448 & 19.2 & 2.3 & 2 & -0.2 \\
\hline 120 & 35 & 0.11 & 497 & 20.3 & 4.2 & 1 & -0.2 \\
\hline 150 & 35 & 0.11 & 497 & 19.8 & 4.2 & 2 & -0.3 \\
\hline 180 & 35 & 0.11 & 549 & 19.7 & 4.2 & 2 & -0.2 \\
\hline
\end{tabular}




\begin{tabular}{|l|l|l|l|l|l|l|l|}
\hline 210 & 35 & 0.11 & 549 & 19.7 & 4.2 & 3 & -0.2 \\
\hline $\begin{array}{l}\text { Batch PC 2 } \\
\text { Table 16: Process parameter of design batch PC 2 in granurex technology }\end{array}$ \\
\begin{tabular}{|l|l|l|l|l|l|l|} 
Time \\
\end{tabular} & $\begin{array}{l}\text { Slit air } \\
\text { Temp. }\end{array}$ \\
\hline 10 & 35 & $\begin{array}{l}\text { Slit air } \\
\text { volume }\end{array}$ & $\begin{array}{l}\text { Disc } \\
\text { RPM }\end{array}$ & $\begin{array}{l}\text { Product } \\
\text { temp }\end{array}$ & $\begin{array}{l}\text { Spray } \\
\text { rate(RPM) }\end{array}$ & $\begin{array}{l}\text { Feed } \\
\text { rate(rpm) }\end{array}$ & $\begin{array}{l}\text { Chamber } \\
\text { statics }\end{array}$ \\
\hline 30 & 35 & 0.11 & 370 & 21 & 3.4 & 2 & -0.3 \\
\hline 50 & 35 & 0.11 & 370 & 20.2 & 3 & 2 & -0.3 \\
\hline 70 & 35 & 0.11 & 370 & 20.6 & 3.8 & 1 & -0.3 \\
\hline 90 & 35 & 0.11 & 460 & 20.8 & 3.8 & 1 & -0.3 \\
\hline 120 & 35 & 0.11 & 460 & 20.9 & 5 & 1 & -0.3 \\
\hline
\end{tabular}

Batch PC 3

Table 17: Process parameter for design batch PC 3 in granurex technology

\begin{tabular}{|l|l|l|l|l|l|l|l|}
\hline Time & $\begin{array}{l}\text { Slit air } \\
\text { Temp. }\end{array}$ & $\begin{array}{l}\text { Slit } \mathbf{C} \\
\text { volume }\end{array}$ & $\begin{array}{l}\text { Disc } \\
\text { RPM }\end{array}$ & $\begin{array}{l}\text { Product } \\
\text { temp }\end{array}$ & $\begin{array}{l}\text { Spray } \\
\text { rate(RPM) }\end{array}$ & $\begin{array}{l}\text { Feed } \\
\text { rate(rpm) }\end{array}$ & $\begin{array}{l}\text { Chamber } \\
\text { statics }\end{array}$ \\
\hline 20 & 35 & 0.11 & 480 & 21 & 4 & 3 & -0.3 \\
\hline 40 & 35 & 0.11 & 480 & 20.6 & 4 & 5 & -0.2 \\
\hline 60 & 35 & 0.11 & 480 & 19.8 & 4 & 3 & -0.3 \\
\hline 80 & 35 & 0.11 & 507 & 20 & 4 & 3 & -0.4 \\
\hline
\end{tabular}

Batch PC 4

Table 18: Process parameter for design batch PC 4 in granurex technology

\begin{tabular}{|l|l|l|l|l|l|l|l|}
\hline Time & $\begin{array}{l}\text { Slit air } \\
\text { Temp. }\end{array}{ }^{\circ} \mathbf{C}$ & $\begin{array}{l}\text { Slit air } \\
\text { volume }\end{array}$ & $\begin{array}{l}\text { Disc } \\
\text { RPM }\end{array}$ & $\begin{array}{l}\text { Product } \\
\text { temp }\end{array}$ & $\begin{array}{l}\text { Spray } \\
\text { rate(RPM) }\end{array}$ & $\begin{array}{l}\text { Feed } \\
\text { rate(rpm) }\end{array}$ & $\begin{array}{l}\text { Chamber } \\
\text { statics }\end{array}$ \\
\hline 20 & 35 & 0.11 & 370 & 24 & 5 & 6 & -1 \\
\hline 40 & 35 & 0.1 & 370 & 21.4 & 7 & 3 & -1 \\
\hline 60 & 35 & 0.1 & 370 & 20.5 & 7 & 6 & -0.9 \\
\hline 90 & 35 & 0.1 & 460 & 20.4 & 7 & 7 & -0.9 \\
\hline 120 & 35 & 0.1 & 460 & 20 & 7 & 7 & -0.7 \\
\hline 150 & 35 & 0.1 & 544 & 20 & 7 & 7 & -0.7 \\
\hline
\end{tabular}

Batch PC 5

Table 19: Process parameter of design batch PC 5 in granurex technology

\begin{tabular}{|l|l|l|l|l|l|l|l|}
\hline Time & $\begin{array}{l}\text { Slit air } \\
\text { Temp. }^{\circ} \text { C }\end{array}$ & $\begin{array}{l}\text { Slit air } \\
\text { volume }\end{array}$ & $\begin{array}{l}\text { Disc } \\
\text { RPM }\end{array}$ & $\begin{array}{l}\text { Product } \\
\text { temp }\end{array}$ & $\begin{array}{l}\text { Spray } \\
\text { rate(RPM) }\end{array}$ & $\begin{array}{l}\text { Feed } \\
\text { rate(rpm) }\end{array}$ & $\begin{array}{l}\text { Chamber } \\
\text { statics }\end{array}$ \\
\hline 20 & 35 & 0.1 & 377 & 20 & 5 & 2 & -0.1 \\
\hline 40 & 35 & 0.1 & 400 & 21.5 & 6 & 2 & -0.3 \\
\hline 60 & 35 & 0.1 & 451 & 21.9 & 6 & 2 & -0.3 \\
\hline 90 & 35 & 0.1 & 490 & 22 & 7 & 2 & -0.3 \\
\hline 120 & 35 & 0.1 & 512 & 20.7 & 9 & 7 & -0.3 \\
\hline
\end{tabular}

Batch PC 6

Table 20:Process parameter of design batch PC 6 in granurex technology

\begin{tabular}{|l|l|l|l|l|l|l|l|}
\hline Time & $\begin{array}{l}\text { Slit air } \\
\text { Temp. }^{\circ} \text { C }\end{array}$ & $\begin{array}{l}\text { Slit air } \\
\text { volume }\end{array}$ & $\begin{array}{l}\text { Disc } \\
\text { RPM }\end{array}$ & $\begin{array}{l}\text { Product } \\
\text { temp }\end{array}$ & $\begin{array}{l}\text { Spray } \\
\text { rate(RPM) }\end{array}$ & $\begin{array}{l}\text { Feed } \\
\text { rate(rpm) }\end{array}$ & $\begin{array}{l}\text { Chamber } \\
\text { statics }\end{array}$ \\
\hline 20 & 35 & 0.11 & 370 & 22.1 & 5 & 1 & -0.4 \\
\hline 40 & 35 & 0.11 & 370 & 21.6 & 5 & 1 & -0.4 \\
\hline 60 & 35 & 0.11 & 370 & 21.6 & 5 & 1 & -0.4 \\
\hline
\end{tabular}




\begin{tabular}{|l|l|l|l|l|l|l|l|}
\hline 90 & 35 & 0.11 & 460 & 21.7 & 6 & 1 & -0.4 \\
\hline 120 & 35 & 0.11 & 460 & 20.9 & 7.5 & 5 & -0.4 \\
\hline 150 & 35 & 0.11 & 544 & 20.6 & 8.5 & 7 & -0.4 \\
\hline 180 & 35 & 0.11 & 544 & 20.5 & 9 & 10 & -0.4 \\
\hline
\end{tabular}

Batch PC 7

Table 21: process parameter of design batch PC 7 in granurex technology

\begin{tabular}{|l|l|l|l|l|l|l|l|}
\hline Time & $\begin{array}{l}\text { Slit air } \\
\text { Temp. }^{\circ} \text { C }\end{array}$ & $\begin{array}{l}\text { Slit air } \\
\text { volume }\end{array}$ & $\begin{array}{l}\text { Disc } \\
\text { RPM }\end{array}$ & $\begin{array}{l}\text { Product } \\
\text { temp }\end{array}$ & $\begin{array}{l}\text { Spray } \\
\text { rate(RPM) }\end{array}$ & $\begin{array}{l}\text { Feed } \\
\text { rate(rpm) }\end{array}$ & $\begin{array}{l}\text { Chamber } \\
\text { statics }\end{array}$ \\
\hline 20 & 35 & 0.11 & 388 & 19.8 & 5 & 5 & -0.4 \\
\hline 40 & 35 & 0.11 & 436 & 20.4 & 5 & 5 & -0.4 \\
\hline 60 & 35 & 0.11 & 436 & 20.3 & 5 & 5 & -0.4 \\
\hline 90 & 35 & 0.11 & 518 & 20 & 5 & 5 & -0.4 \\
\hline 120 & 35 & 0.11 & 518 & 19.9 & 5 & 5 & -0.4 \\
\hline
\end{tabular}

Batch PC 8

Table 22: process parameter of design batch PC 8 in granurex technology

\begin{tabular}{|l|l|l|l|l|l|l|l|}
\hline Time & $\begin{array}{l}\text { Slit air } \\
\text { Temp. }^{\circ} \text { C }\end{array}$ & $\begin{array}{l}\text { Slit air } \\
\text { volume }\end{array}$ & $\begin{array}{l}\text { Disc } \\
\text { RPM }\end{array}$ & $\begin{array}{l}\text { Product } \\
\text { temp }\end{array}$ & $\begin{array}{l}\text { Spray } \\
\text { rate(RPM) }\end{array}$ & $\begin{array}{l}\text { Feed } \\
\text { rate(rpm) }\end{array}$ & $\begin{array}{l}\text { Chamber } \\
\text { statics }\end{array}$ \\
\hline 20 & 35 & 0.12 & 364 & 21 & 5.5 & 2 & -0.5 \\
\hline 40 & 35 & 0.12 & 364 & 20.3 & 5.5 & 3 & -0.5 \\
\hline 60 & 35 & 0.12 & 502 & 20.3 & 5.5 & 3 & -0.5 \\
\hline 90 & 35 & 0.12 & 502 & 20.4 & 6.5 & 7 & -0.5 \\
\hline 120 & 35 & 0.12 & 592 & 20.6 & 7 & 10 & -0.5 \\
\hline
\end{tabular}

The design batches was prepared and then evaluated after that ER coating performed on those DoE batches.

Table 23: Composition used for ER coating

\begin{tabular}{|c|c|c|c|c|c|c|c|c|c|c|}
\hline \multirow[t]{2}{*}{ Batches } & \multicolumn{2}{|c|}{ EC 45 cps } & \multicolumn{2}{|c|}{ White wax } & \multicolumn{2}{|c|}{ Isopropyl alcohol } & \multicolumn{2}{|c|}{ Total weight } & \multicolumn{2}{|c|}{$\begin{array}{c}\text { Talc } \\
(0.5 \%)\end{array}$} \\
\hline & $\mathrm{mg}$ & $\mathrm{gm}$ & $\mathrm{mg}$ & $\mathrm{gm}$ & $\mathrm{mg}$ & $\mathrm{gm}$ & $\mathrm{mg}$ & $\mathrm{gm}$ & $\mathrm{mg}$ & gm \\
\hline PC 1 & 20 & 60 & 10 & 30 & QS & 2160 & 285 & 855 & 1.43 & 4.28 \\
\hline PC 2 & 20 & 60 & 3 & 9 & QS & 1656 & 278 & 834 & 1.39 & 4.17 \\
\hline PC 3 & 8 & 24 & 10 & 30 & QS & 1296 & 273 & 819 & 1.37 & 4.1 \\
\hline PC 4 & 8 & 24 & 3 & 9 & QS & 729 & 296 & 888 & 1.48 & 4.44 \\
\hline PC 5 & 20 & 60 & 10 & 30 & QS & 1512 & 315 & 945 & 1.58 & 4.73 \\
\hline PC 6 & 20 & 60 & 3 & 9 & QS & 1656 & 308 & 924 & 1.54 & 4.62 \\
\hline PC 7 & 8 & 24 & 3 & 9 & QS & 1584 & 266 & 798 & 1.33 & 3.99 \\
\hline PC 8 & 14 & 42 & 6.5 & 19.5 & QS & 1476 & 290.5 & 871.5 & 1.45 & 4.36 \\
\hline PC 9 & 8 & 24 & 10 & 30 & QS & 1296 & 303 & 909 & 1.52 & 4.55 \\
\hline
\end{tabular}

Above batches were evaluated for dissolution studies and extractability studies.

Drug release studies for design batch PC 1 to PC 8 


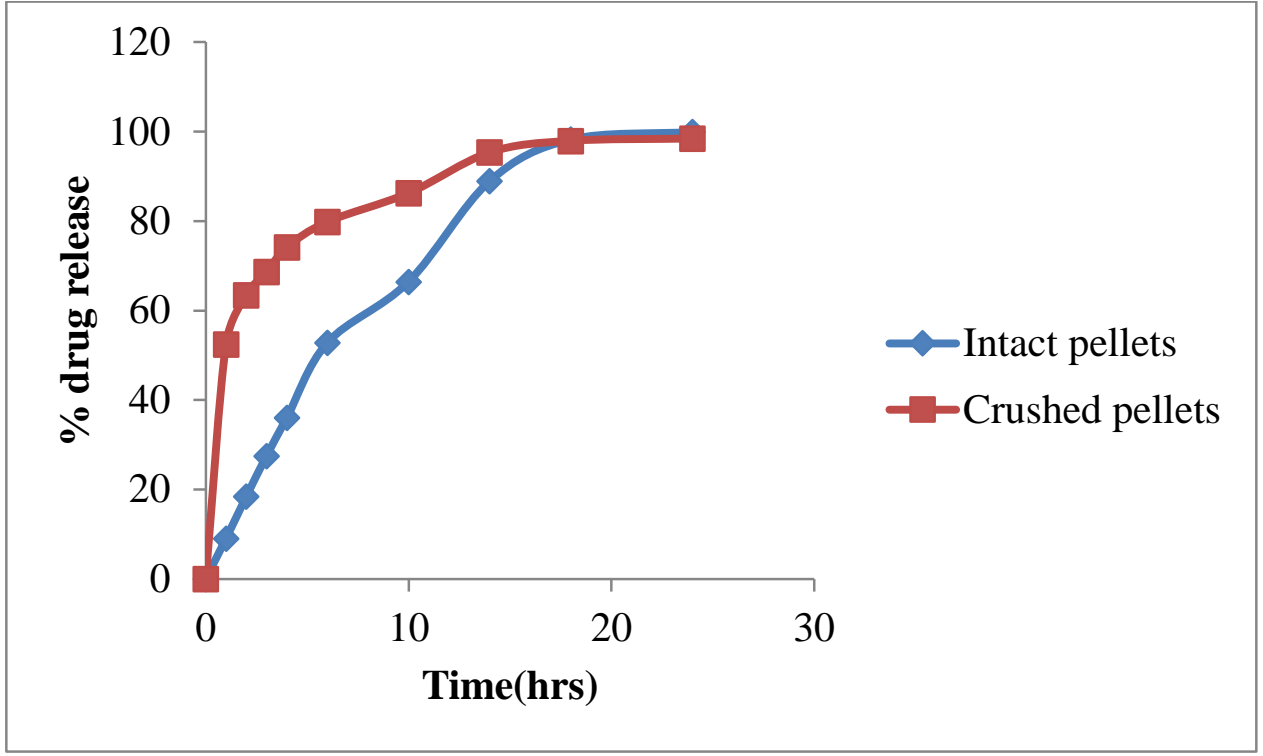

Figure 6: Graphical representation of Design batch PC 1

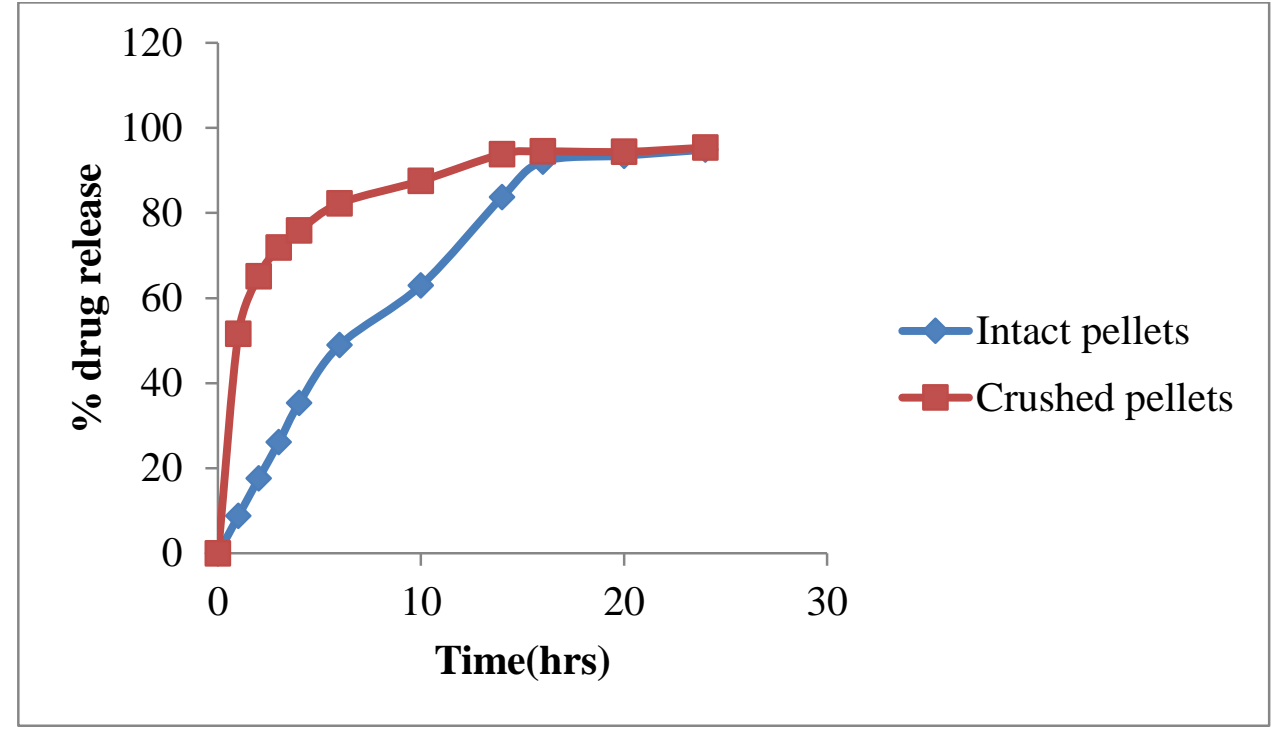

Figure 7: Graphical representation of design batch PC 2 


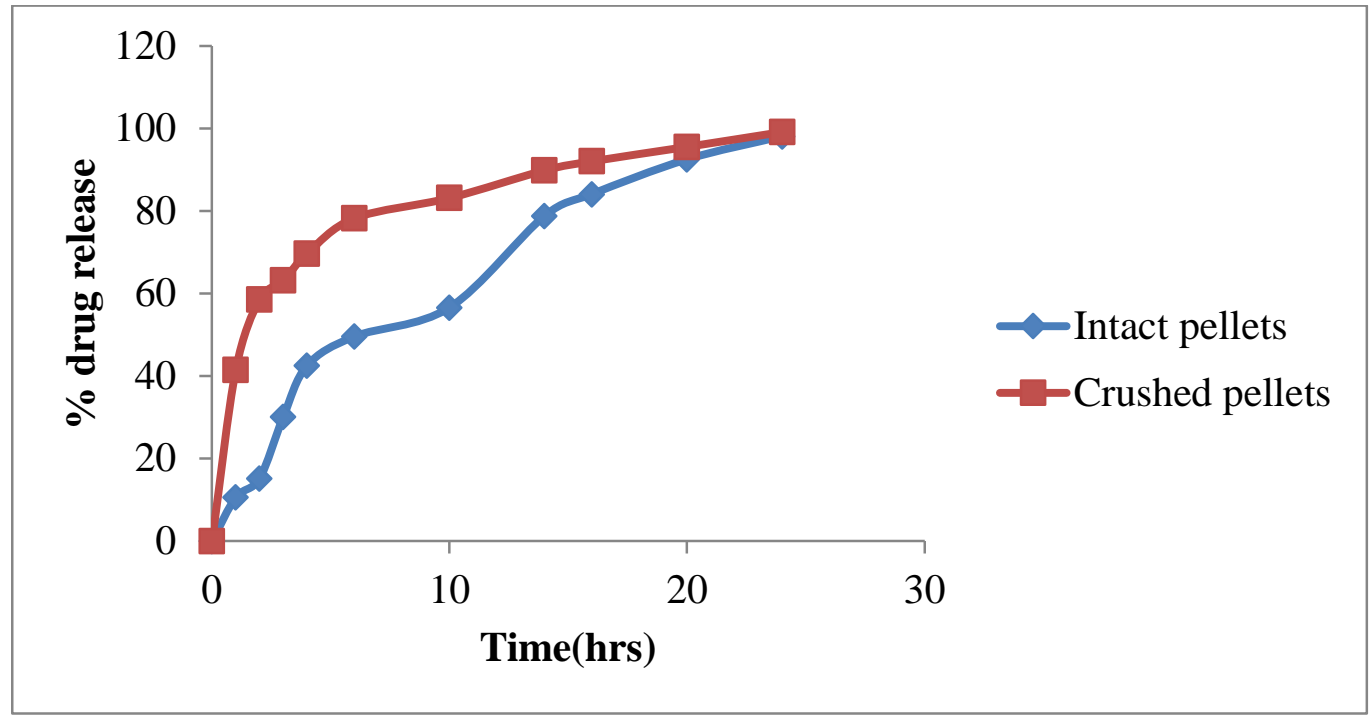

Figure 8: Graphical representation of design batch PC 3

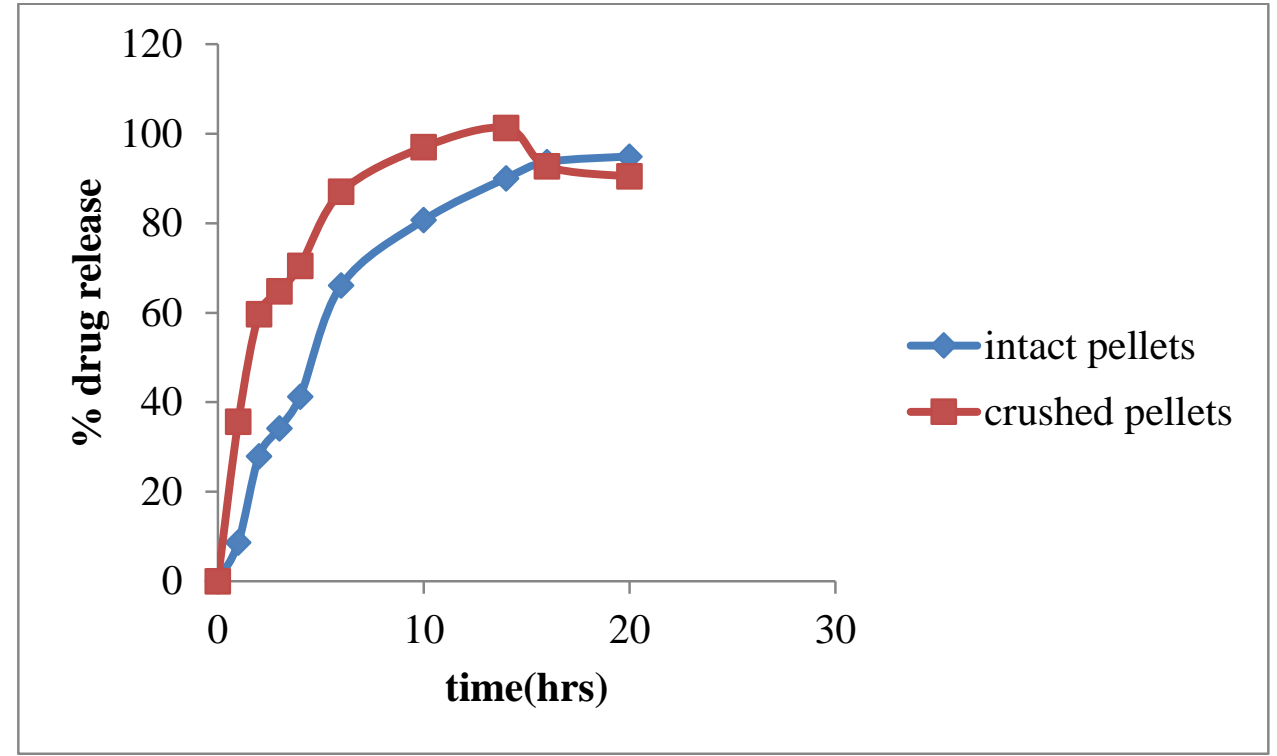

Figure 9: Graphical representation of design batch PC 4 


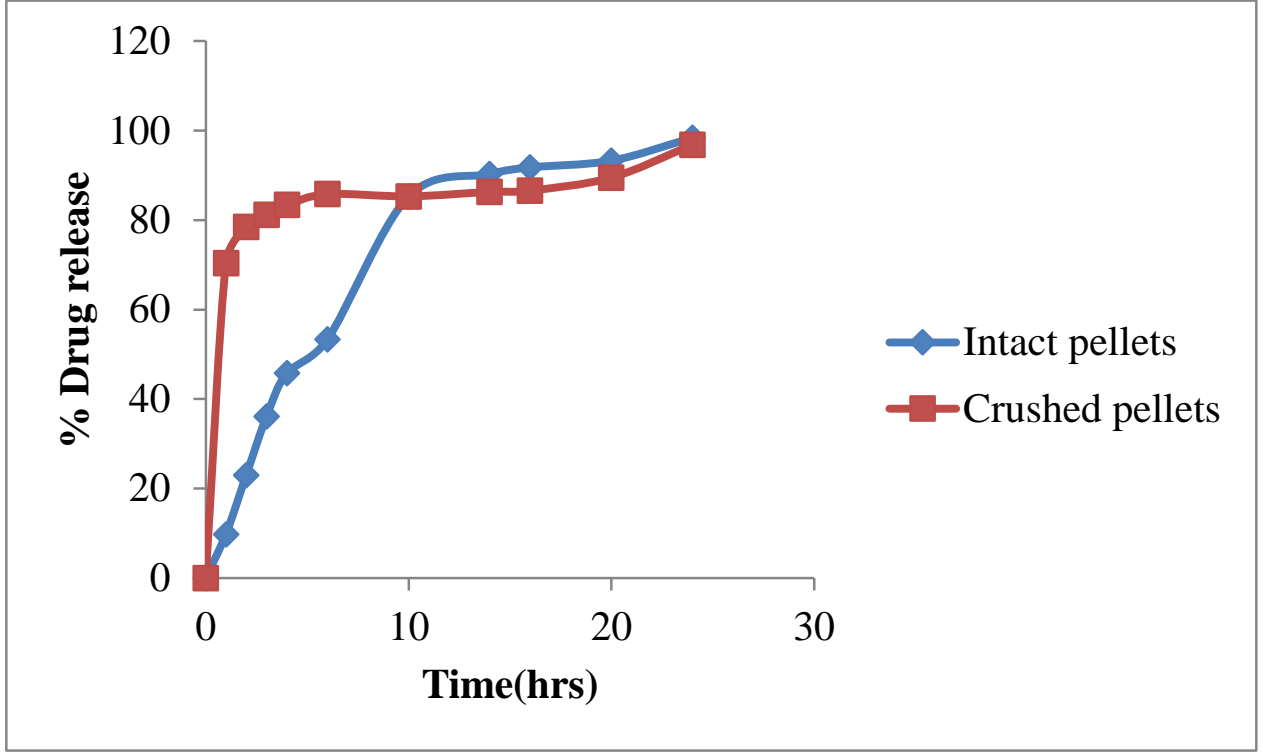

Figure 10: Graphical representation of design batch PC 5

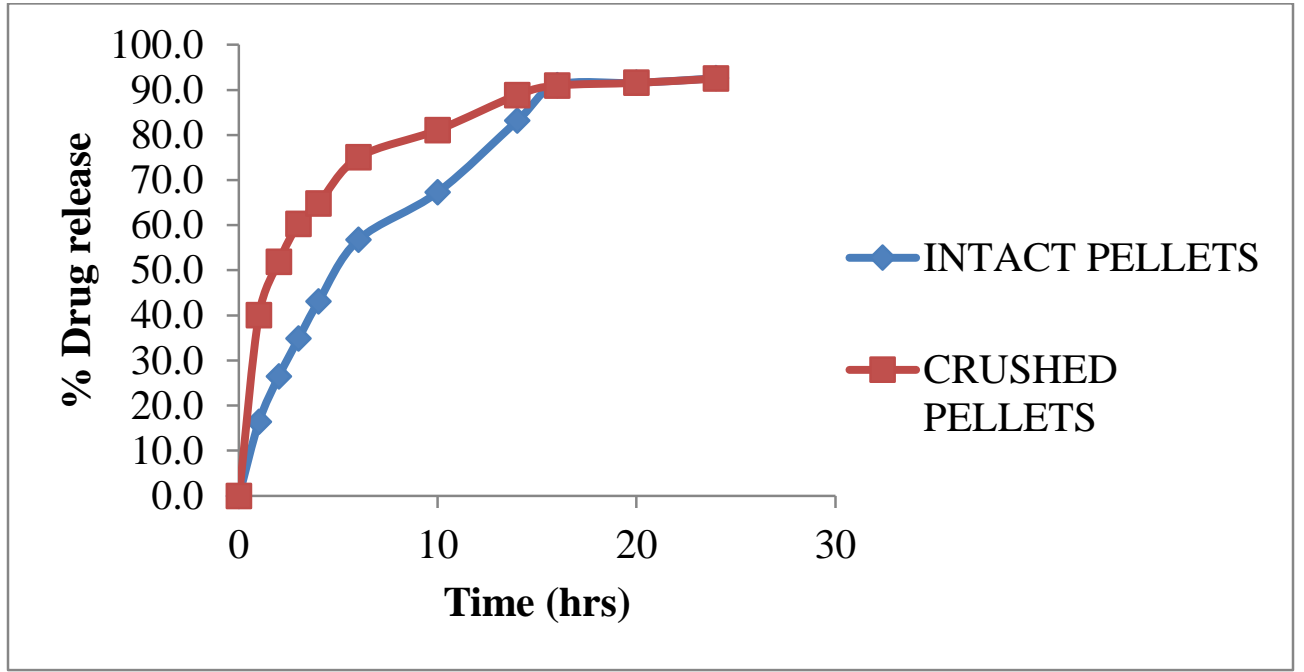

Figure 11: Graphical representation of batch PC 6 


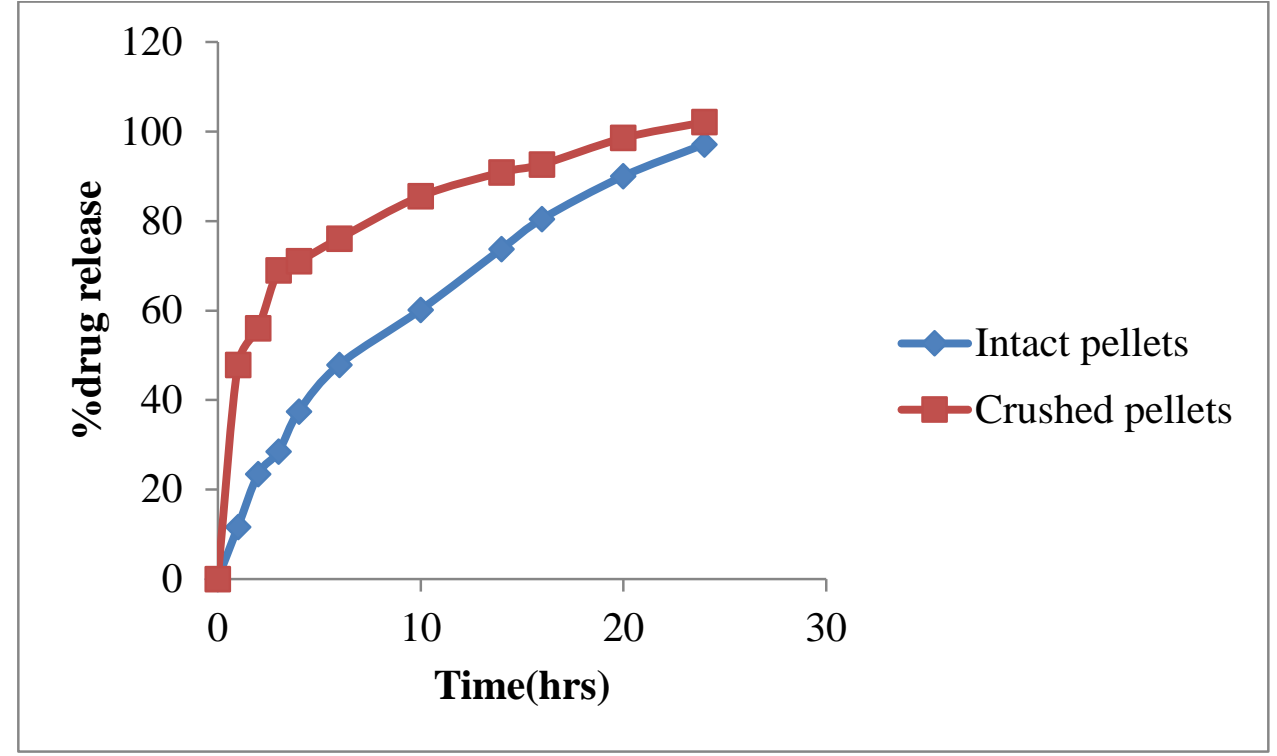

Figure 12: Graphical representation of batch PC 7

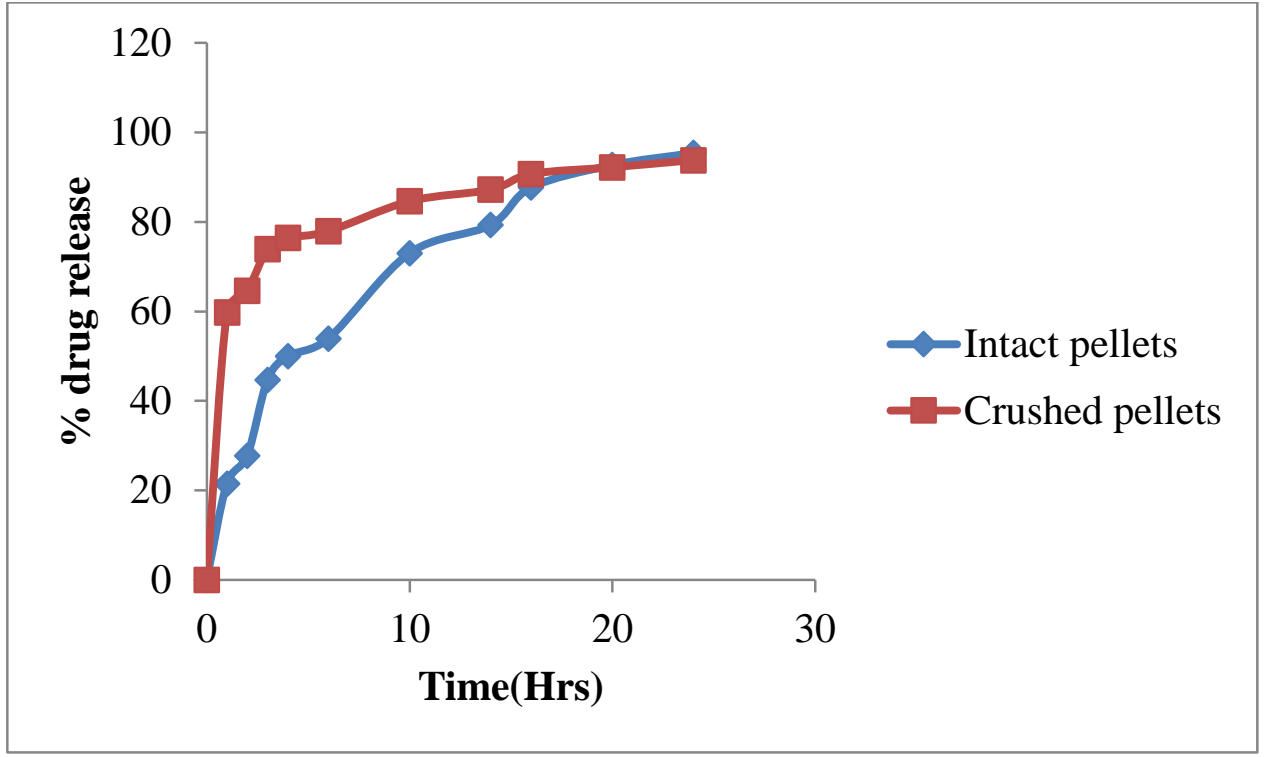

Figure 13: Graphical representation of batch PC 8

\section{$\underline{\text { Extraction study }}$}

Table 24 Extraction study design batch PC 1

\begin{tabular}{|l|l|l|l|l|}
\hline & & $\%$ Extraction & & \\
\hline & Stage & $1 \mathrm{~h}$ & & \\
\hline Water(level 1 solvent) & Intact & 36.2 & & \\
\hline & Crushed & 56.1 & & \\
\hline $40 \%$ Ethanol(level 2 solvent) & Intact & 79.9 & & \\
\hline & Crushed & 84.4 & & \\
\hline $0.1 \mathrm{~N} \mathrm{HCl(level} \mathrm{3} \mathrm{solvent)}$ & Intact & 29.5 & & \\
\hline & Crushed & 38.4 & & \\
\hline extraction studies & condition-media volume-300ml(Distilled water) \\
\hline
\end{tabular}




\begin{tabular}{|c|c|c|c|c|}
\hline level 1 solvent(water) & \multicolumn{3}{|l|}{ RPM-50 } & \\
\hline stock solution & \multicolumn{2}{|l|}{ dilutions } & \multicolumn{2}{|c|}{ lambda max } \\
\hline $100 \mathrm{mg}$ in $300 \mathrm{ml}$ & $1 \mathrm{ml}$ to $10 \mathrm{ml}$ & $3 \mathrm{ml}$ to $10 \mathrm{ml}$ & $243 \mathrm{~nm}$ & \\
\hline \multirow[t]{2}{*}{$333.33 \mathrm{mcg} / \mathrm{ml}$} & $33.33 \mathrm{mcg} / \mathrm{ml}$ & $9.99 \mathrm{mcg} / \mathrm{ml}$ & & \\
\hline & \multicolumn{2}{|l|}{ Absorbance } & \multicolumn{2}{|c|}{ \% drug release } \\
\hline Time point(hr) & Intact & Crushed & Intact & Crushed \\
\hline 0 & 0 & 0 & 0 & 0 \\
\hline 1 & 0.1912 & 0.3152 & 36.2 & 56.14 \\
\hline level 2 solvent $(40 \%$ ethanol $)$ & \multicolumn{4}{|c|}{ condition- media volume- $300 \mathrm{ml}(40 \%$ ethanol $)$} \\
\hline & \multicolumn{3}{|l|}{ RPM-50 } & \\
\hline & \multicolumn{2}{|l|}{ Absorbance } & \multicolumn{2}{|c|}{$\%$ drug release } \\
\hline Time point(hr) & Intact & Crushed & Intact & Crushed \\
\hline 0 & 0 & 0 & 0 & 0 \\
\hline 1 & 0.593 & 0.8074 & 42.46 & 57.83 \\
\hline level 3 solvent $(0.1 \mathrm{~N} \mathrm{HCl})$ & \multicolumn{4}{|c|}{ condition- media volume- $300 \mathrm{ml}(0.1 \mathrm{~N} \mathrm{HCl})$} \\
\hline & \multicolumn{3}{|l|}{ RPM-50 } & \\
\hline & \multicolumn{2}{|l|}{ Absorbance } & \multicolumn{2}{|c|}{$\%$ drug release } \\
\hline Time point(hr) & Intact & Crushed & ntact & Crushed \\
\hline 0 & 0 & 0 & 0 & 0 \\
\hline 1 & 0.1916 & 0.2489 & 29.52 & 38.35 \\
\hline
\end{tabular}

Table 25: Extraction study of design batch PC 2

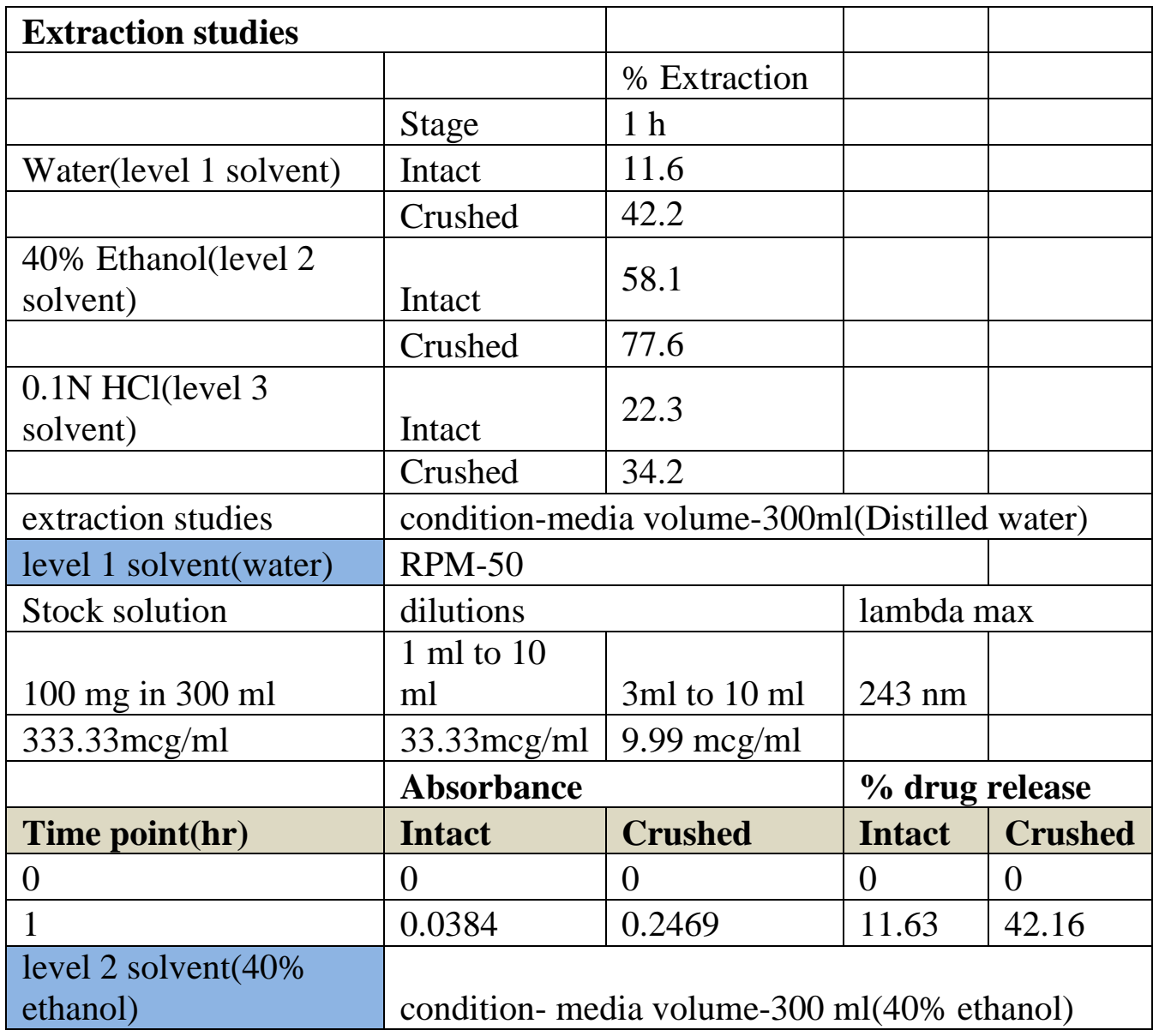




\begin{tabular}{|c|c|c|c|c|}
\hline \multirow[b]{3}{*}{ Time point(hr) } & \multicolumn{3}{|c|}{ RPM-50 } & \\
\hline & \multicolumn{2}{|c|}{ Absorbance } & \multicolumn{2}{|c|}{ \% drug release } \\
\hline & Intact & Crushed & Intact & Crushed \\
\hline 0 & 0 & 0 & 0 & 0 \\
\hline 1 & 0.6741 & 0.902 & 48.26 & 64.61 \\
\hline
\end{tabular}

Table 26: Extraction study of design batch PC 3

\begin{tabular}{|c|c|c|c|c|}
\hline \multirow[t]{2}{*}{ Extraction studies } & & & & \\
\hline & & $\%$ Extraction & & \\
\hline & Stage & $1 \mathrm{~h}$ & & \\
\hline \multirow[t]{2}{*}{ Water(level 1 solvent) } & Intact & 19.5 & & \\
\hline & Crushed & 41.0 & & \\
\hline \multirow[t]{2}{*}{$40 \%$ Ethanol(level 2 solvent) } & Intact & 47.6 & & \\
\hline & Crushed & 49.9 & & \\
\hline \multirow{2}{*}{$0.1 \mathrm{~N} \mathrm{HCl}($ level 3 solvent) } & Intact & 19.5 & & \\
\hline & Crushed & 46.2 & & \\
\hline Extraction studies & \multicolumn{4}{|c|}{ Condition-media volume-300ml(Distilled water) } \\
\hline Level 1 solvent(water) & \multicolumn{3}{|l|}{ RPM-50 } & \\
\hline Stock solution & \multicolumn{2}{|l|}{ dilutions } & \multicolumn{2}{|c|}{ lambda max } \\
\hline $100 \mathrm{mg}$ in $300 \mathrm{ml}$ & $1 \mathrm{ml}$ to $10 \mathrm{ml}$ & $3 \mathrm{ml}$ to $10 \mathrm{ml}$ & $243 \mathrm{~nm}$ & \\
\hline \multirow[t]{2}{*}{$333.33 \mathrm{mcg} / \mathrm{ml}$} & $33.33 \mathrm{mcg} / \mathrm{ml}$ & $9.99 \mathrm{mcg} / \mathrm{ml}$ & & \\
\hline & \multicolumn{2}{|l|}{ Absorbance } & \multicolumn{2}{|c|}{ \% drug release } \\
\hline Time point(hr) & Intact & Crushed & Intact & Crushed \\
\hline 0 & 0 & 0 & 0 & 0 \\
\hline 1 & 0.087 & 0.221 & 19.45 & 40.99 \\
\hline \multirow[t]{3}{*}{ Level 2 solvent $(40 \%$ ethanol $)$} & \multicolumn{4}{|c|}{ Condition- media volume- $300 \mathrm{ml}(40 \%$ ethanol $)$} \\
\hline & \multicolumn{3}{|l|}{ RPM-50 } & \\
\hline & \multicolumn{2}{|l|}{ Absorbance } & \multicolumn{2}{|c|}{$\%$ drug release } \\
\hline Time point(hr) & Intact & Crushed & Intact & Crushed \\
\hline 0 & 0 & 0 & 0 & 0 \\
\hline 1 & 0.6636 & 0.6965 & 47.55 & 49.89 \\
\hline \multirow[t]{3}{*}{ Level 3 solvent $(0.1 \mathrm{~N} \mathrm{HCl})$} & \multicolumn{4}{|c|}{ condition- media volume- $300 \mathrm{ml}(0.1 \mathrm{~N} \mathrm{HCl})$} \\
\hline & \multicolumn{3}{|l|}{ RPM-50 } & \\
\hline & \multicolumn{2}{|l|}{ Absorbance } & \multicolumn{2}{|c|}{$\%$ drug release } \\
\hline Time point(hr) & Intact & Crushed & Intact & \begin{tabular}{|l|} 
Crushed \\
\end{tabular} \\
\hline 0 & 0 & 0 & 0 & 0 \\
\hline 1 & 0.132 & 0.2996 & 19.45 & 46.16 \\
\hline
\end{tabular}

Table 27: Extraction study of design batch PC 4

\begin{tabular}{|l|l|l|l|}
\hline Extraction studies & & & \\
\hline & & $\%$ Extraction & Absorbance \\
\hline & Stage & $1 \mathrm{~h}$ & \\
\hline Water(level 1 solvent) & Intact & 12.7 & 0.045 \\
\hline
\end{tabular}




\begin{tabular}{|l|l|l|l|}
\hline & Crushed & 23.95 & 0.115 \\
\hline $\begin{array}{l}\text { 40\% Ethanol(level 2 } \\
\text { solvent) }\end{array}$ & Intact & 40.48 & 0.599 \\
\hline & Crushed & 54.5 & 0.7135 \\
\hline $\begin{array}{l}0.1 \mathrm{~N} \mathrm{HCl(level} \mathrm{3} \\
\text { solvent) }\end{array}$ & Intact & 21.42 & 0.1052 \\
\hline & Crushed & 35.6 & 0.2311 \\
\hline
\end{tabular}

Table 28: Extraction study of design batch PC 5

\begin{tabular}{|c|c|c|c|c|}
\hline \multicolumn{5}{|l|}{ Extraction studies } \\
\hline & & $\%$ Extraction & & \\
\hline & Stage & $1 \mathrm{~h}$ & & \\
\hline \multirow[t]{2}{*}{ Water(level 1 solvent) } & Intact & 26.7 & & \\
\hline & Crushed & 35.9 & & \\
\hline \multirow[t]{2}{*}{$40 \%$ Ethanol(level 2 solvent) } & Intact & 62.8 & & \\
\hline & Crushed & 87.9 & & \\
\hline \multirow[t]{2}{*}{$0.1 \mathrm{~N} \mathrm{HCl}($ level 3 solvent $)$} & Intact & 32.7 & & \\
\hline & Crushed & 48.2 & & \\
\hline Extraction studies & \multicolumn{3}{|c|}{ Condition-media volume-300ml(Distilled water } & \\
\hline Level 1 solvent(water) & \multicolumn{3}{|l|}{ RPM-50 } & \\
\hline Stock solution & \multicolumn{2}{|l|}{ Dilutions } & \multicolumn{2}{|c|}{ lambda max } \\
\hline $100 \mathrm{mg}$ in $300 \mathrm{ml}$ & $1 \mathrm{ml}$ to $10 \mathrm{ml}$ & $3 \mathrm{ml}$ to $10 \mathrm{ml}$ & $243 \mathrm{~nm}$ & \\
\hline \multirow[t]{2}{*}{$333.33 \mathrm{mcg} / \mathrm{ml}$} & $33.33 \mathrm{mcg} / \mathrm{ml}$ & $9.99 \mathrm{mcg} / \mathrm{ml}$ & & \\
\hline & \multicolumn{2}{|l|}{ Absorbance } & \multicolumn{2}{|c|}{$\%$ drug release } \\
\hline Time point(hr) & Intact & Crushed & Intact & Crushed \\
\hline 0 & 0 & 0 & 0 & 0 \\
\hline 1 & 0.132 & 0.189 & 26.68 & 35.85 \\
\hline \multirow[t]{3}{*}{ Level 2 solvent( $40 \%$ ethanol) } & \multicolumn{4}{|c|}{ Condition- media volume-300 $\mathrm{ml}(40 \%$ ethanol $)$} \\
\hline & \multicolumn{3}{|l|}{ RPM-50 } & \\
\hline & \multicolumn{2}{|l|}{ Absorbance } & \multicolumn{2}{|c|}{$\%$ drug release } \\
\hline Time point(hr) & Intact & Crushed & Intact & Crushed \\
\hline 0 & 0 & 0 & 0 & 0 \\
\hline 1 & 0.8222 & 1.1502 & 62.81 & 87.86 \\
\hline \multirow[t]{3}{*}{ Level 3 solvent $(0.1 \mathrm{~N} \mathrm{HCl})$} & \multicolumn{4}{|c|}{ Condition- media volume- $300 \mathrm{ml}(0.1 \mathrm{~N} \mathrm{HCl})$} \\
\hline & \multicolumn{3}{|l|}{ RPM-50 } & \\
\hline & \multicolumn{2}{|l|}{ Absorbance } & \multicolumn{2}{|c|}{$\%$ drug release } \\
\hline Time point(hr) & Intact & Crushed & Intact & Crushed \\
\hline 0 & 0 & 0 & 0 & 0 \\
\hline 1 & 0.212 & 0.313 & 32.66 & 48.22 \\
\hline
\end{tabular}


Table 29: Extraction study of design batch PC 6

\begin{tabular}{|l|l|r|r|}
\hline Extraction studies & & & \\
\hline & & Absorbance & \% Extraction \\
\hline & Stage & & $1 \mathrm{~h}$ \\
\hline Water(level 1 solvent) & Intact & 0.057 & 14.63 \\
\hline & Crushed & 0.199 & 37.45 \\
\hline $40 \%$ Ethanol(level 2 solvent) & Intact & 0.5248 & 40.091 \\
\hline & Crushed & 0.4027 & 30.76 \\
\hline $0.1 \mathrm{~N} \mathrm{HCl(level} \mathrm{3} \mathrm{solvent)}$ & Intact & 0.223 & 34.35 \\
\hline & Crushed & 0.302 & 45.13 \\
\hline
\end{tabular}

Table 30: Extraction study of design batch PC 7

\begin{tabular}{|c|c|c|c|c|}
\hline \multirow[t]{2}{*}{ Extraction studies } & & & & \\
\hline & & $\%$ Extraction & & \\
\hline & Stage & $1 \mathrm{~h}$ & & \\
\hline \multirow[t]{2}{*}{ Water(level 1 solvent) } & Intact & 30.38 & & \\
\hline & Crushed & 58.68 & & \\
\hline \multirow[t]{2}{*}{$40 \%$ Ethanol(level 2 solvent) } & Intact & 79.94 & & \\
\hline & Crushed & 84.71 & & \\
\hline \multirow[t]{2}{*}{$0.1 \mathrm{~N} \mathrm{HCl(level} 3$ solvent) } & Intact & 25.48 & & \\
\hline & Crushed & 44.48 & & \\
\hline Extraction studies & \multicolumn{4}{|c|}{ Condition-media volume-300ml(Distilled water) } \\
\hline Level 1 solvent(water) & \multicolumn{3}{|l|}{ RPM-50 } & \\
\hline Stock solution & \multicolumn{2}{|l|}{ Dilutions } & \multicolumn{2}{|c|}{ lambda max } \\
\hline $100 \mathrm{mg}$ in $300 \mathrm{ml}$ & $1 \mathrm{ml}$ to $10 \mathrm{ml}$ & $3 \mathrm{ml}$ to $10 \mathrm{ml}$ & $243 \mathrm{~nm}$ & \\
\hline \multirow[t]{2}{*}{$333.33 \mathrm{mcg} / \mathrm{ml}$} & $33.33 \mathrm{mcg} / \mathrm{ml}$ & $9.99 \mathrm{mcg} / \mathrm{ml}$ & & \\
\hline & \multicolumn{2}{|l|}{ Absorbance } & \multicolumn{2}{|c|}{$\%$ drug release } \\
\hline Time point(hr) & Intact & Crushed & Intact & Crushed \\
\hline 0 & 0 & 0 & 0 & 0 \\
\hline 1 & 0.155 & 0.331 & 30.38 & 58.68 \\
\hline \multirow[t]{3}{*}{ Level 2 solvent $(40 \%$ ethanol $)$} & \multicolumn{4}{|c|}{ Condition- media volume- $300 \mathrm{ml}(40 \%$ ethanol $)$} \\
\hline & \multicolumn{3}{|l|}{ RPM-50 } & \\
\hline & \multicolumn{2}{|l|}{ Absorbance } & \multicolumn{2}{|c|}{$\%$ drug release } \\
\hline Time point(hr) & Intact & Crushed & Intact & Crushed \\
\hline 0 & 0 & 0 & 0 & 0 \\
\hline 1 & 0.6611 & 0.7021 & 79.94 & 84.71 \\
\hline \multirow[t]{3}{*}{ Level 3 solvent $(0.1 \mathrm{~N} \mathrm{HCl})$} & \multicolumn{4}{|c|}{ Condition- media volume- $300 \mathrm{ml}(0.1 \mathrm{~N} \mathrm{HCl})$} \\
\hline & \multicolumn{3}{|l|}{ RPM-50 } & \\
\hline & \multicolumn{2}{|l|}{ Absorbance } & \multicolumn{2}{|c|}{$\%$ drug release } \\
\hline Time point(hr) & Intact & Crushed & Intact & Crushed \\
\hline
\end{tabular}




\begin{tabular}{|l|l|l|l|l|}
\hline 0 & 0 & 0 & 0 & 0 \\
\hline 1 & 0.1655 & 0.2999 & 25.48 & 44.48 \\
\hline
\end{tabular}

Table 31: Extraction study of design batch PC 8

\begin{tabular}{|c|c|c|c|c|}
\hline \multirow[t]{2}{*}{\begin{tabular}{|l|} 
Extraction studies \\
\end{tabular}} & & \multirow{2}{*}{$\%$ Extraction } & & \\
\hline & & & & \\
\hline & Stage & $1 \mathrm{~h}$ & & \\
\hline \multirow{2}{*}{ Water(level 1 solvent) } & Intact & 23.5 & & \\
\hline & Crushed & 41.0 & & \\
\hline \multirow[t]{2}{*}{$\begin{array}{l}40 \% \text { Ethanol(level } 2 \\
\text { solvent) }\end{array}$} & Intact & 67.7 & & \\
\hline & Crushed & 84.7 & & \\
\hline \multirow[t]{2}{*}{$0.1 \mathrm{~N} \mathrm{HCl(level} 3$ solvent) } & Intact & 30.2 & & \\
\hline & Crushed & 34.2 & & \\
\hline & & & & \\
\hline extraction studies & \multicolumn{4}{|c|}{ Condition-media volume-300ml(Distilled water) } \\
\hline Level 1 solvent(water) & \multicolumn{3}{|l|}{ RPM-50 } & \\
\hline Stock solution & \multicolumn{2}{|l|}{ Dilutions } & \multicolumn{2}{|c|}{ lambda max } \\
\hline $100 \mathrm{mg}$ in $300 \mathrm{ml}$ & \begin{tabular}{|l|l|}
$\begin{array}{l}\mathrm{ml} \text { to } 10 \\
\mathrm{ml}\end{array}$ \\
\end{tabular} & $3 \mathrm{ml}$ to $10 \mathrm{ml}$ & $243 \mathrm{~nm}$ & \\
\hline \multirow{2}{*}{$333.33 \mathrm{mcg} / \mathrm{ml}$} & $33.33 \mathrm{mcg} / \mathrm{ml}$ & $9.99 \mathrm{mcg} / \mathrm{ml}$ & & \\
\hline & \multicolumn{2}{|l|}{ Absorbance } & \multicolumn{2}{|c|}{ \% drug release } \\
\hline Time point(hr) & Intact & Crushed & Intact & Crushed \\
\hline 0 & 0 & 0 & 0 & 0 \\
\hline 1 & 0.112 & 0.21 & 23.47 & 40.99 \\
\hline \multirow[t]{3}{*}{$\begin{array}{l}\text { Level } 2 \text { solvent }(40 \% \\
\text { ethanol })\end{array}$} & \multicolumn{4}{|c|}{ Condition- media volume- $300 \mathrm{ml}(40 \%$ ethanol) } \\
\hline & \multicolumn{3}{|l|}{ RPM-50 } & \\
\hline & \multicolumn{2}{|l|}{ Absorbance } & \multicolumn{2}{|c|}{$\%$ drug release } \\
\hline Time point(hr) & Intact & Crushed & Intact & Crushed \\
\hline 0 & 0 & 0 & 0 & 0 \\
\hline 1 & 0.556 & 0.702 & 67.66 & 84.71 \\
\hline \multirow[t]{3}{*}{ Level 3 solvent $(0.1 \mathrm{~N} \mathrm{HCl})$} & \multicolumn{4}{|c|}{ Condition- media volume- $300 \mathrm{ml}(0.1 \mathrm{~N} \mathrm{HCl})$} \\
\hline & \multicolumn{3}{|l|}{ RPM-50 } & \\
\hline & \multicolumn{2}{|l|}{ Absorbance } & \multicolumn{2}{|c|}{$\%$ drug release } \\
\hline Time point(hr) & Intact & Crushed & Intact & Crushed \\
\hline 0 & 0 & 0 & 0 & 0 \\
\hline 1 & 0.196 & 0.212 & 30.18 & 32.65 \\
\hline
\end{tabular}

Process parameter of which can be set on the preparation of design batches are as follows: 
Batch PC 1

Table 32: Process parameter for extended release coating of design batch PC 1

\begin{tabular}{|l|l|l|l|l|l|l|}
\hline $\begin{array}{l}\text { Tim } \\
\text { e }\end{array}$ & $\begin{array}{l}\text { Air } \\
\text { flow }\end{array}$ & $\begin{array}{l}\text { Inlet air } \\
\operatorname{temp}\left({ }^{\circ} \mathbf{C}\right)\end{array}$ & $\begin{array}{l}\text { Column } \\
\text { height }(\mathbf{c m})\end{array}$ & $\begin{array}{l}\text { Spray } \\
\text { rate }\end{array}$ & $\begin{array}{l}\text { Product } \\
\operatorname{temp}\left({ }^{\circ} \mathbf{C}\right)\end{array}$ & $\begin{array}{l}\text { Exhaust air } \\
\text { temp }\left({ }^{\circ} \mathbf{C}\right)\end{array}$ \\
\hline 0 & 0 & 0 & 0 & 0 & 0 & 0 \\
\hline 20 & 80 & 30 & 18 & 10.89 & 25.9 & 25.5 \\
\hline 40 & 80 & 30 & 18 & 10.89 & 25.9 & 25.7 \\
\hline 60 & 82 & 30.1 & 20 & 10.89 & 27.2 & 27.3 \\
\hline 80 & 79 & 30.5 & 20 & 12.77 & 27.5 & 27.5 \\
\hline 100 & 86 & 38.6 & 20 & 23.61 & 32.3 & 30.3 \\
\hline 120 & 90 & 38.3 & 20 & 30.25 & 32.5 & 32.3 \\
\hline 140 & 91 & 38 & 20 & 30.24 & 32.1 & 31.9 \\
\hline 160 & 90 & 38.2 & 20 & 30.24 & 32.1 & 31.8 \\
\hline
\end{tabular}

Batch PC 2

Table 33: Process parameter for extended release coating of design batch PC 2

\begin{tabular}{|l|l|l|l|l|l|l|}
\hline Time & $\begin{array}{l}\text { Air } \\
\text { flow }\end{array}$ & $\begin{array}{l}\text { Inlet air } \\
\text { temp }\left({ }^{\circ} \mathbf{C}\right)\end{array}$ & $\begin{array}{l}\text { Column } \\
\text { height }\end{array}$ & Spray rate & $\begin{array}{l}\text { Product } \\
\text { temp }\left({ }^{\circ} \mathbf{C}\right)\end{array}$ & Exhaust air temp $\left({ }^{\circ} \mathbf{C}\right)$ \\
\hline 0 & 0 & 0 & 0 & 0 & 0 & 0 \\
\hline 10 & 96 & 40.5 & 18 & 15 & 33.3 & 33.3 \\
\hline 30 & 98 & 40 & 18 & 15 & 33.2 & 32.8 \\
\hline 50 & 84 & 40.8 & 19 & 20 & 33.4 & 33 \\
\hline 70 & 92 & 40.9 & 18 & 20 & 33.1 & 32.9 \\
\hline 90 & 90 & 40.8 & 18 & 20 & 33.4 & 32.8 \\
\hline
\end{tabular}

Batch PC 3

Table 34: Process parameter for extended release coating of design batch PC 3

\begin{tabular}{|l|l|l|l|l|l|l|}
\hline Time & $\begin{array}{l}\text { Air } \\
\text { flow }\end{array}$ & $\begin{array}{l}\text { Inlet air } \\
\operatorname{temp}\left({ }^{\circ} \mathbf{C}\right)\end{array}$ & $\begin{array}{l}\text { Column } \\
\text { height }\end{array}$ & $\begin{array}{l}\text { Spray } \\
\text { rate }\end{array}$ & $\begin{array}{l}\text { Product } \\
\operatorname{temp}\left({ }^{\circ} \mathbf{C}\right)\end{array}$ & Exhaust air temp $\left({ }^{\circ} \mathbf{C}\right)$ \\
\hline 0 & 0 & 0 & 0 & 0 & 0 & 0 \\
\hline 20 & 98 & 40.1 & 18 & 30.82 & 30.1 & 30 \\
\hline 40 & 98 & 40.2 & 18 & 30.82 & 30 & 30.1 \\
\hline 60 & 95 & 40.4 & 19 & 30.8 & 31.2 & 31.1 \\
\hline 90 & 93 & 40.2 & 18 & 30.8 & 31.3 & 31.2 \\
\hline 120 & 97 & 40 & 18 & 30.8 & 31.2 & 30.1 \\
\hline
\end{tabular}

Batch PC 4

Table 35: Process parameter for extended release coating of design batch PC 4

\begin{tabular}{|l|l|l|l|l|l|l|}
\hline Time & $\begin{array}{l}\text { Air } \\
\text { flow }\end{array}$ & $\begin{array}{l}\text { Inlet air } \\
\operatorname{temp}\left({ }^{\circ} \mathbf{C}\right)\end{array}$ & $\begin{array}{l}\text { Column } \\
\text { height }\end{array}$ & $\begin{array}{l}\text { Spray } \\
\text { rate }\end{array}$ & $\begin{array}{l}\text { Product } \\
\operatorname{temp}\left({ }^{\circ} \mathbf{C}\right)\end{array}$ & $\begin{array}{l}\text { Exhaust air } \\
\text { temp }\left({ }^{\circ} \mathbf{C}\right)\end{array}$ \\
\hline 0 & 0 & 0 & 0 & 0 & 0 & 0 \\
\hline 20 & 99 & 40.1 & 18 & 30.86 & 30.1 & 30 \\
\hline 40 & 99 & 40.2 & 18 & 30.86 & 30 & 30.1 \\
\hline 60 & 95 & 40.2 & 19 & 30.8 & 31.2 & 31.1 \\
\hline 90 & 95 & 30.41 & 18 & 30.8 & 31.3 & 31.2 \\
\hline
\end{tabular}

Batch PC 5

Table 36: Process parameter for extended release coating of design batch PC 5

\begin{tabular}{l|l|l|l|l|l|l} 
Time & Air & Inlet air & Column & Spray & Product & Exhaust air $\operatorname{temp}\left({ }^{\circ} \mathbf{C}\right)$
\end{tabular}




\begin{tabular}{|l|l|l|l|l|l|l|}
\hline & flow & $\operatorname{temp}\left({ }^{\circ} \mathbf{C}\right)$ & height & rate & $\operatorname{temp}\left({ }^{\circ} \mathbf{C}\right)$ & \\
\hline 0 & 0 & 0 & 0 & 0 & 0 & 0 \\
\hline 20 & 99 & 40 & 19 & 30 & 29.1 & 28 \\
\hline 40 & 97 & 40.1 & 19 & 30 & 30 & 29.1 \\
\hline 60 & 97 & 40.4 & 20 & 30 & 30.2 & 30 \\
\hline 90 & 93 & 40.2 & 20 & 30 & 30.3 & 29.2 \\
\hline 120 & 97 & 40 & 20 & 30.8 & 31 & 30.1 \\
\hline
\end{tabular}

Batch PC 6

Table 37: Process parameter for extended release coating of design batch PC 6

\begin{tabular}{|l|l|l|l|l|l|l|}
\hline Time & $\begin{array}{l}\text { Air } \\
\text { flow }\end{array}$ & $\begin{array}{l}\text { Inlet air } \\
\text { temp }\left({ }^{\circ} \mathbf{C}\right)\end{array}$ & $\begin{array}{l}\text { Column } \\
\text { height }\end{array}$ & $\begin{array}{l}\text { Spray } \\
\text { rate }\end{array}$ & $\begin{array}{l}\text { Product } \\
\text { temp }\left({ }^{\circ} \mathbf{C}\right)\end{array}$ & Exhaust air temp $\left({ }^{\circ} \mathbf{C}\right)$ \\
\hline 0 & 0 & 0 & 0 & 0 & 0 & 0 \\
\hline 20 & 90 & 30 & 19 & 15.79 & 24.9 & 25.3 \\
\hline 40 & 95 & 30 & 19 & 14.32 & 25 & 25.5 \\
\hline 60 & 92 & 29.8 & 20 & 15.63 & 27 & 27 \\
\hline 80 & 97 & 30.2 & 20 & 14.93 & 27.2 & 27.2 \\
\hline 100 & 96 & 35.6 & 20 & 15 & 31.3 & 30.2 \\
\hline 120 & 95 & 37.8 & 20 & 15 & 32 & 31 \\
\hline 140 & 93 & 37.5 & 20 & 13 & 32 & 31.3 \\
\hline
\end{tabular}

Batch PC 7

Table 38: Process parameter for extended release coating of design batch PC 7

\begin{tabular}{|l|l|l|l|l|l|l|}
\hline Time & $\begin{array}{l}\text { Air } \\
\text { flow }\end{array}$ & $\begin{array}{l}\text { Inlet air } \\
\text { temp }\left({ }^{\circ} \mathbf{C}\right)\end{array}$ & $\begin{array}{l}\text { Column } \\
\text { height }\end{array}$ & $\begin{array}{l}\text { Spray } \\
\text { rate }\end{array}$ & $\begin{array}{l}\text { Product } \\
\operatorname{temp}\left({ }^{\circ} \mathbf{C}\right)\end{array}$ & Exhaust air temp $\left({ }^{\circ} \mathbf{C}\right)$ \\
\hline 0 & 0 & 0 & 0 & 0 & 0 & 0 \\
\hline 10 & 98 & 40.3 & 19 & 18 & 35.2 & 33.1 \\
\hline 30 & 100 & 40.1 & 18 & 18 & 35 & 32.5 \\
\hline 50 & 100 & 41 & 19 & 19 & 34.1 & 32.9 \\
\hline 70 & 92 & 40.3 & 19 & 20 & 34.9 & 33 \\
\hline 90 & 95 & 43.2 & 19.2 & 20 & 35 & 33.1 \\
\hline
\end{tabular}

\section{Batch PC 8}

Table 39: Process parameter for extended release coating of design batch 8

\begin{tabular}{|l|l|l|l|l|l|l|}
\hline Time & $\begin{array}{l}\text { Air } \\
\text { flow }\end{array}$ & $\begin{array}{l}\text { Inlet air } \\
\operatorname{temp}\left({ }^{\circ} \mathbf{C}\right)\end{array}$ & $\begin{array}{l}\text { Column } \\
\text { height }\end{array}$ & $\begin{array}{l}\text { Spray } \\
\text { rate }\end{array}$ & $\begin{array}{l}\text { Product } \\
\operatorname{temp}\left({ }^{\circ} \mathbf{C}\right)\end{array}$ & Exhaust air temp $\left({ }^{\circ} \mathbf{C}\right)$ \\
\hline 0 & 0 & 0 & 0 & 0 & 0 & 0 \\
\hline 20 & 98 & 40.3 & 19 & 35 & 30.6 & 30.2 \\
\hline 40 & 99 & 40 & 19 & 30 & 31 & 30.4 \\
\hline 60 & 95 & 40.5 & 20 & 30 & 31.1 & 31.7 \\
\hline 90 & 94 & 35.23 & 20 & 28 & 33 & 31.3 \\
\hline
\end{tabular}

Dissolution data and extraction studies provide information regarding the drug release in presence of different media. It was observed that drug release profile of intact pellets and crushed pellets are nearly similar. Apart from this extraction studies provides significant drug release in different solvents. In extraction studies it was observed that dose dumping in $40 \%$ ethanol was prevented and significant release of drug. 


\section{SUMMARY AND CONCLUSION (Buhse, 2016)}

The present study showed that drug containing carbopol 974P NF pellets were successfully prepared. Carbopol 974P NF matrix found effective to protect the drug in ethanol. while effectively releasing the drug up to $24 \mathrm{hrs}$. The \%drug release was studied in appropriate medias simulating the conditions and maintaining the release at precise rate. The pellets were prepared using granurex technique. The optimization of the drug loaded carbopol 974P NF pellets was done using $2^{3}$ full factorial design with critical variables like Concentration of carbopol polymer and concentration of white wax and concentration of ethyl cellulose 45 cps was investigated. During formulation it was revealed that increasing the carbopol concentration up to certain level, hard pellets were observed. While ethyl cellulose 45 cps concentration affects \% drug release of the pellets by forming the coat on the drug layered pellets. The present study shows the use of carbopol 974P NF as a tool to protect the drug entity and thereby helping to release the drug in the desired site. This type of approach can be used for retard the drug release. An in-vitro performance test revealed that the optimized batch shows less than $10 \%$ drug release in 1 hours and about 94.9\% in 20 hours. Apart from this, it was observed that difference between the intact pellets and crushed pellets were less. Hence, we successfully formulated drug loaded carbopol 974P NF matrix based pellets which deter the abuse and has a potential of retard the drug release by using carbopol 974P NF.

\section{REFERENCE}

1. Aiyalu, R., Govindarjan, A., \& Ramasamy, A. (2016). Formulation and evaluation of topical herbal gel for the treatment of arthritis in animal model. Brazilian Journal of Pharmaceutical Sciences, 52(3), 493-507. https://doi.org/10.1590/s198482502016000300015

2. Balakrishnan, P., Park, E. K., Song, C. K., Ko, H. J., Hahn, T. W., Song, K. W., \& Cho, H. J. (2015). Carbopol-Incorporated thermoreversible gel for intranasal drug delivery. Molecules, 20(3), 4124-4135. https://doi.org/10.3390/molecules20034124

3. Belwal, S., Suman, V., Krishna, V. V., Rajesh, B., \& Rama, N. (2016). Optimization of moisture content to strengthening the granules prepared in rotary drum granulator. International Journal of Chemical Sciences, 14(3), 1549-1568.

4. Buhse, C. (2016). Office of Pharmaceutical Quality Science and Research: Abuse Deterrent Formulations ADF Expectations :

5. Dey, N. S., Majumdar, S., \& Rao, M. E. B. (2008). Multiparticulate Drug Delivery Systems 
for Controlled Release. Tropical Journal of Pharmaceutical Research, 7(September), 1067-1075. https://doi.org/10.4314/tjpr.v7i3.14692

6. El Mafaldi, S., Hayert, M., \& Poncelet, D. (2003). Fluidization Control in the Wurster Coating Process. Chem. Ind., 57(12), 641-644. https://doi.org/10.2298/HEMIND0312641e

7. For, T., Degree, T. H. E., Doctor, O. F., Philosophy, O. F., \& Li, L. (2015). Particle motion , coating and drying in Wurster fluidized beds - An experimental and discrete element modeling study.

8. Guidance, D. (2016). General Principles for Evaluating the Abuse Deterrence of Generic Solid Oral Opioid Drug Products Guidance for Industry General Principles for Evaluating the Abuse Deterrence of Generic Solid Oral Opioid Drug Products Guidance for Industry, (March).

9. Identification, C., Identification, H., \& Measures, F. A. (2013). Safety data sheet, 1-6.

10. Murtaza, G. (2012). Ethylcellulose Microparticles : a Review, 69(1), 11-22.

11. PELLETS from microcrystalline cellulose Cellets: the safe and easy way to multiparticular dosage forms. (n.d.).

12. Prajapati, H. N., Patel, D. P., Patel, N. G., Dalrymple, D. D., \& Serajuddin, A. T. M. (2011). Effect of Difference in Fatty Acid Chain Lengths of Medium-Chain Lipids on Lipid-Surfactant-Water Phase Diagrams and Drug Solubility. Journal of Excipients and Food Chemicals, 2(3), 73-88. Retrieved from https://ojs.abo.fi/index.php/jefc/article/view/91

13. Ravi Teja Pusapati*, T. V. R. (2014). Fluidized bed processing : A review. Indian Journal of Research in Pharmacy and Biotechnology, 5674(August), 1360-1365.

14. Sahoo, C. K., Rao, S. R. M., Sudhakar, M., \& Bhaskar, J. (2016). Advances in granulation technology. Research Journal of Pharmacy and Technology, 9(5), 571-580. https://doi.org/10.5958/0974-360X.2016.00108.6

15. Services, H. (2017). Assessment of Abuse Potential of Drugs Guidance for Industry Assessment of Abuse Potential of Drugs Guidance for Industry, (January).

16. Throckmorton, D. C. (2016). Pre-Market Evaluation of Abuse- Deterrent Properties of Opioid Drug Products - Framing the Meeting Overall Messages.

17. Werner, D. (2006). Sugar spheres: a versatile excipient for oral pellet medications with modified release kinetics. Pharmaceutical Technology Europe. Retrieved from http://www.pharmtech.com/pharmtech/Analytical/Sugar-spheres-a-versatile-excipient-fororal-pelle/ArticleStandard/Article/detail/319888 
18. Winiecki, S. K. (n.d.). Understanding Abuse Deterrent Opioids.

\section{AJPTR is}

- Peer-reviewed

- bimonthly

- Rapid publication

Submit your manuscript at: editor@ajptr.com

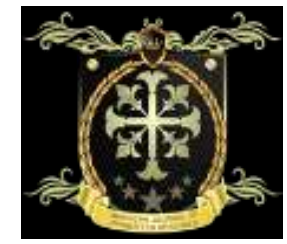

